\title{
General iterative algorithms for mixed equilibrium problems, a general system of generalized equilibria and fixed point problems
}

\author{
Hui-Ying Hu' ${ }^{1}$, Lu-Chuan Ceng ${ }^{1 *}$ and Yan-Lai Song ${ }^{2}$
}

\section{"Correspondence:}

zenglc@hotmail.com

'Department of Mathematics,

Shanghai Normal University,

Shanghai, 200234, China

Full list of author information is

available at the end of the article

\begin{abstract}
In this paper, we introduce and analyze a general iterative algorithm for finding a common solution of a finite family of mixed equilibrium problems, a general system of generalized equilibria and a fixed point problem of nonexpansive mappings in a real Hilbert space. Under some appropriate conditions, we derive the strong convergence of the sequence generated by the proposed algorithm to a common solution, which also solves some optimization problem. The result presented in this paper improves and extends some corresponding ones in the earlier and recent literature.

MSC: 49J30; 47H10;47H15
\end{abstract}

Keywords: mixed equilibrium problem; nonexpansive mapping; general system of generalized equilibria; fixed point

\section{Introduction}

Let $H$ be a real Hilbert space with the inner product $\langle\cdot, \cdot\rangle$ and the norm $\|\cdot\|$. Let $C$ be a nonempty, closed and convex subset of $H$, and let $T: C \rightarrow C$ be a nonlinear mapping. Throughout this paper, we use $F(T)$ to denote the fixed point set of $T$. A mapping $T: C \rightarrow$ $C$ is said to be nonexpansive if

$$
\|T x-T y\| \leq\|x-y\|, \quad \forall x, y \in C .
$$

Let $F: C \times C \rightarrow R$ be a real-valued bifunction and $\varphi: C \rightarrow R$ be a real-valued function, where $R$ is a set of real numbers. The so-called mixed equilibrium problem (MEP) is to find $x \in C$ such that

$$
F(x, y)+\varphi(y)-\varphi(x) \geq 0, \quad \forall y \in C,
$$

which was considered and studied in [1,2]. The set of solutions of MEP (1.2) is denoted by $\operatorname{MEP}(F, \varphi)$. In particular, whenever $\varphi \equiv 0, \operatorname{MEP}(1.2)$ reduces to the equilibrium problem (EP) of finding $x \in C$ such that

$$
F(x, y) \geq 0, \quad \forall y \in C,
$$

@2014 Hu et al.; licensee Springer. This is an Open Access article distributed under the terms of the Creative Commons Attribution License (http://creativecommons.org/licenses/by/2.0), which permits unrestricted use, distribution, and reproduction in any medium, provided the original work is properly cited. 
which was considered and studied in [3-7]. The set of solutions of the EP is denoted by $\mathrm{EP}(F)$. Given a mapping $A: C \rightarrow H$, let $F(x, y)=\langle A x, y-x\rangle$ for all $x, y \in C$. Then $z \in \operatorname{EP}(F)$ if and only if $\langle A x, y-x\rangle \geq 0$ for all $y \in C$. Numerous problems in physics, optimization and economics reduce to finding a solution of the EP.

Throughout this paper, assume that $F: C \times C \rightarrow R$ is a bifunction satisfying conditions (A1)-(A4) and that $\varphi: C \rightarrow R$ is a lower semicontinuous and convex function with restriction (B1) or (B2), where

(A1) $F(x, x)=0$ for all $x \in C$;

(A2) $F$ is monotone, i.e., $F(x, y)+F(y, x) \leq 0$, for any $x, y \in C$;

(A3) $F$ is upper hemicontinuous, i.e., for each $x, y, z \in C$,

$$
\limsup _{t \rightarrow 0} F(t z+(1-t) x, y) \leq F(x, y)
$$

(A4) $F(x, \cdot)$ is convex and lower semicontinuous for each $x \in C$;

(B1) for each $x \in H$ and $r>0$, there exist a bounded subset $D_{x} \subset C$ and $y_{x} \in C$ such that for any $z \in C \backslash D_{x}$,

$$
F\left(z, y_{x}\right)+\varphi\left(y_{x}\right)-\varphi(z)+\frac{1}{r}\left\langle y_{x}-z, z-x\right\rangle<0
$$

(B2) $C$ is a bounded set.

The mappings $\left\{T_{n}\right\}_{n=1}^{\infty}$ are said to be an infinite family of nonexpansive self-mappings on $C$ if

$$
\left\|T_{n} x-T_{n} y\right\| \leq\|x-y\|, \quad \forall x, y \in C, n \geq 1
$$

and denoted by $F\left(T_{n}\right)$ is a fixed point set of $T_{n}$, i.e., $F\left(T_{n}\right)=\left\{x \in H: T_{n} x=x\right\}$. Finding an optimal point in the intersection $\bigcap_{n=1}^{\infty} F\left(T_{n}\right)$ of fixed point sets of mappings $T_{n}, n \geq 1$, is a matter of interest in various branches of sciences.

Recently, many authors considered some iterative methods for finding a common element of the set of solutions of MEP (1.2) and the set of fixed points of nonexpansive mappings; see, e.g., $[2,8,9]$ and the references therein.

A mapping $A: C \rightarrow H$ is said to be:

(i) Monotone if

$$
\langle A x-A y, x-y\rangle \geq 0, \quad \forall x, y \in C .
$$

(ii) Strongly monotone if there exists a constant $\eta>0$ such that

$$
\langle A x-A y, x-y\rangle \geq \eta\|x-y\|^{2}, \quad \forall x, y \in C .
$$

In such a case, $A$ is said to be $\eta$-strongly monotone.

(iii) Inverse-strongly monotone if there exists a constant $\zeta>0$ such that

$$
\langle A x-A y, x-y\rangle \geq \zeta\|A x-A y\|^{2}, \quad \forall x, y \in C .
$$

In such a case, $A$ is said to be $\zeta$-inverse-strongly monotone. 
Let $A: C \rightarrow H$ be a nonlinear mapping. The classical variational inequality problem (VIP) is to find $x^{*} \in C$ such that

$$
\left\langle A x^{*}, y-x^{*}\right\rangle \geq 0, \quad \forall y \in C
$$

We use $\operatorname{VI}(C, A)$ to denote the set of solutions to VIP (1.4). One can easily see that VIP (1.4) is equivalent to a fixed point problem, the origin of which can be traced back to Lions and Stampacchia [10]. That is, $u \in C$ is a solution to VIP (1.4) if and only if $u$ is a fixed point of the mapping $P_{C}(I-\lambda A)$, where $\lambda>0$ is a constant. Variational inequality theory has been studied quite extensively and has emerged as an important tool in the study of a wide class of obstacle, unilateral, free, moving, equilibrium problems. Not only are the existence and uniqueness of solutions important topics in the study of VIP (1.4), but also how to actually find a solution of VIP (1.4) is important. Up to now, there have been many iterative algorithms in the literature for finding approximate solutions of VIP (1.4) and its extended versions; see, e.g., [3, 11-14].

Recently, Ceng and Yao [8] introduced and studied the general system of generalized equilibria (GSEP) as follows: Let $C$ be a nonempty closed convex subset of a real Hilbert space $H$. Let $\Theta_{1}, \Theta_{2}: C \times C \rightarrow R$ be two bifunctions, $B_{1}, B_{2}: C \rightarrow H$ be two nonlinear mappings. Consider the following problem of finding $\left(x^{*}, y^{*}\right) \in C \times C$ such that

$$
\begin{cases}\Theta_{1}\left(x^{*}, x\right)+\left\langle B_{1} y^{*}, x-x^{*}\right\rangle+\frac{1}{\mu_{1}}\left\langle x^{*}-y^{*}, x-x^{*}\right\rangle \geq 0, & \forall x \in C \\ \Theta_{2}\left(y^{*}, y\right)+\left\langle B_{2} x^{*}, y-y^{*}\right\rangle+\frac{1}{\mu_{2}}\left\langle y^{*}-x^{*}, y-y^{*}\right\rangle \geq 0, & \forall y \in C\end{cases}
$$

where $\mu_{1}>0, \mu_{2}>0$ are two constants. In particular, whenever $\Theta_{1}=\Theta_{2}=0$, GSEP (1.5) reduces to the following general system of variational inequalities (GSVI): find $\left(x^{*}, y^{*}\right) \in$ $C \times C$ such that

$$
\begin{cases}\left\langle\mu_{1} B_{1} y^{*}+x^{*}-y^{*}, x-x^{*}\right\rangle \geq 0, & \forall x \in C, \\ \left\langle\mu_{2} B_{2} x^{*}+y^{*}-x^{*}, x-y^{*}\right\rangle \geq 0, & \forall y \in C,\end{cases}
$$

where $\mu_{1}$ and $\mu_{2}$ are two positive constants. GSVI (1.6) is considered and studied in [8, 15, 16]. In particular, whenever $B_{1}=B_{2}=A$ and $x^{*}=y^{*}$, GSVI (1.6) reduces to VIP (1.4).

In order to prove our main results in the following sections, we need the following lemmas and propositions.

Proposition 1.1 For given $x \in H$ and $z \in C$ :

(i) $z \in P_{C} x \Leftrightarrow\langle x-z, y-z\rangle \leq 0, \forall y \in C$;

(ii) $z \in P_{C} x \Leftrightarrow\|x-z\|^{2} \leq\|x-y\|^{2}-\|y-z\|^{2}, \forall y \in C$;

(iii) $\left\langle P_{C} x-P_{C} y, x-y\right\rangle \geq\left\|P_{C} x-P_{C} y\right\|^{2}, \forall x, y \in H$.

Consequently, $P_{C}$ is a firmly nonexpansive mapping of $H$ onto $C$ and hence nonexpansive and monotone.

Given a positive number $r>0$. Let $T_{r}^{(\Theta, \varphi)}: H \rightarrow C$ be the solution set of the auxiliary mixed equilibrium problem, that is, for each $x \in H$,

$$
T_{r}^{(\Theta, \varphi)}(x):=\left\{y \in C: \Theta(y, z)+\varphi(z)-\varphi(y)+\frac{1}{r}\langle y-x, z-y\rangle \geq 0, \forall z \in C\right\} .
$$


Proposition 1.2 (see $[2,8]$ ) Let $C$ be a nonempty closed subset of a real Hilbert space $H$. Let $\Theta: C \times C \rightarrow R$ be a bifunction satisfying conditions (A1)-(A4), and let $\varphi: C \rightarrow R$ be a lower semicontinuous and convex function with restriction (B1) or (B2). Then the following hold:

(a) for each $x \in H, T_{r}^{(\Theta, \varphi)} \neq \emptyset$;

(b) $T_{r}^{(\Theta, \varphi)}$ is single-valued;

(c) $T_{r}^{(\Theta, \varphi)}$ is firmly nonexpansive, i.e., for any $x, y \in H$,

$$
\left\|T_{r}^{(\Theta, \varphi)} x-T_{r}^{(\Theta, \varphi)} y\right\|^{2} \leq\left\langle T_{r}^{(\Theta, \varphi)} x-T_{r}^{(\Theta, \varphi)} y, x-y\right\rangle ;
$$

(d) for all $s, t>0$ and $x \in H$,

$$
\left\|T_{s}^{(\Theta, \varphi)} x-T_{t}^{(\Theta, \varphi)} x\right\|^{2} \leq \frac{s-t}{s}\left\langle T_{s}^{(\Theta, \varphi)} x-x, T_{s}^{(\Theta, \varphi)} x-T_{t}^{(\Theta, \varphi)} x\right\rangle ;
$$

(e) $F\left(T_{r}^{(\Theta, \varphi)}\right)=\operatorname{MEP}(\Theta, \varphi)$;

(f) $\operatorname{MEP}(\Theta, \varphi)$ is closed and convex.

Remark 1.1 It is easy to see from conclusions (c) and (d) in Proposition 1.2 that

$$
\left\|T_{r}^{(\Theta, \varphi)} x-T_{r}^{(\Theta, \varphi)} y\right\| \leq\|x-y\|, \quad \forall r>0, x, y \in H
$$

and

$$
\left\|T_{s}^{(\Theta, \varphi)} x-T_{t}^{(\Theta, \varphi)} x\right\| \leq \frac{|s-t|}{s}\left\|T_{s}^{(\Theta, \varphi)} x-x\right\|, \quad \forall s, t>0, x \in H .
$$

Remark 1.2 If $\varphi=0$, then $T_{r}^{(\Theta, \varphi)}$ is rewritten as $T_{r}^{\Theta}$.

Ceng and Yao [8] transformed GSEP (1.5) into a fixed point problem in the following way.

Lemma 1.1 (see [8]) Let C be a nonempty closed convex subset of H. Let $\Theta_{1}, \Theta_{2}: C \times C \rightarrow R$ be two bifunctions satisfying conditions (A1)-(A4), and let the mappings $B_{1}, B_{2}: C \rightarrow H$ be $\zeta_{1}$-inverse strongly monotone and $\zeta_{2}$-inverse strongly monotone, respectively. Let $\mu_{1} \in$ $\left(0,2 \zeta_{1}\right)$ and $\mu_{2} \in\left(0,2 \zeta_{2}\right)$, respectively. Then, for given $x^{*}, y^{*} \in C,\left(x^{*}, y^{*}\right)$ is a solution of GSEP (1.5) if and only if $x^{*}$ is a fixed point of the mapping $G: C \rightarrow C$ defined by

$$
G(x)=T_{\mu_{1}}^{\Theta_{1}}\left(I-\mu_{1} B_{1}\right) T_{\mu_{2}}^{\Theta_{2}}\left(I-\mu_{2} B_{2}\right) x, \quad \forall x \in C,
$$

where $y^{*}=T_{\mu_{2}}^{\Theta_{2}}\left(I-\mu_{2} B_{2}\right) x^{*}$.

Lemma 1.2 (see [8]) For given $x^{*}, y^{*} \in C,\left(x^{*}, y^{*}\right)$ is a solution of GSVI (1.6) if and only if $x^{*}$ is a fixed point of the mapping $G: C \rightarrow C$ defined by

$$
G x=P_{C}\left(I-\mu_{1} B_{1}\right) P_{C}\left(I-\mu_{2} B_{2}\right) x, \quad \forall x \in C,
$$

where $y^{*}=P_{C}\left(x^{*}-\mu_{2} B_{2} x^{*}\right)$ and $P_{C}$ is the projection of $H$ onto $C$. 
Remark 1.3 If $\Theta_{1}, \Theta_{2}: C \times C \rightarrow R$ are two bifunctions satisfying (A1)-(A4), the mappings $B_{1}, B_{2}: C \rightarrow H$ are $\zeta_{1}$-inverse strongly monotone and $\zeta_{2}$-inverse strongly monotone, respectively, then $G: C \rightarrow C$ is a nonexpansive mapping provided $\mu_{1} \in\left(0,2 \zeta_{1}\right)$ and $\mu_{2} \in\left(0,2 \zeta_{2}\right)$.

Throughout this paper, the set of fixed points of the mapping $G$ is denoted by $\Gamma$.

On the other hand, Moudafi [1] introduced the viscosity approximation method for nonexpansive mappings (see also [17] for further developments in both Hilbert spaces and Banach spaces).

A mapping $f: C \rightarrow C$ is called $\alpha$-contractive if there exists a constant $\alpha \in(0,1)$ such that

$$
\|f(x)-f(y)\| \leq \alpha\|x-y\|, \quad \forall x, y \in C .
$$

Let $f$ be a contraction on $C$. Starting with an arbitrary initial $x_{1} \in C$, define a sequence $\left\{x_{n}\right\}$ recursively by

$$
x_{n+1}=\alpha_{n} f\left(x_{n}\right)+\left(1-\alpha_{n}\right) T x_{n}, \quad n \geq 0,
$$

where $T$ is a nonexpansive mapping of $C$ into itself and $\left\{\alpha_{n}\right\}$ is a sequence in $(0,1)$. It is proved $[1,17]$ that under certain appropriate conditions imposed on $\left\{\alpha_{n}\right\}$, the sequence $\left\{x_{n}\right\}$ generated by (1.6) converges strongly to the unique solution $x^{*} \in F(T)$ to the VIP

$$
\left\langle(I-f) x^{*}, x-x^{*}\right\rangle \geq 0, \quad x \in F(T) .
$$

A linear bounded operator $A$ is said to be $\bar{\gamma}$-strongly positive on $H$ if there exists a constant $\bar{\gamma} \in(0,1)$ such that

$$
\langle A x, x\rangle \geq \bar{\gamma}\|x\|^{2}, \quad \forall x \in H
$$

The typical problem is to minimize a quadratic function on a real Hilbert space $H$,

$$
\min _{x \in C} \frac{1}{2}\langle A x, x\rangle-\langle x, u\rangle
$$

where $C$ is a nonempty closed convex subset of $H, u$ is a given point in $H$ and $A$ is a strongly positive bounded linear operator on $H$.

In 2006, Marino and Xu [18] introduced and considered the following general iterative method:

$$
x_{n+1}=\alpha_{n} \gamma f\left(x_{n}\right)+\left(1-\alpha_{n} A\right) T x_{n}, \quad \forall n \geq 0,
$$

where $A$ is a strongly positive bounded linear operator on a real Hilbert space $H, f$ is a contraction on $H$. They proved that the above sequence $\left\{x_{n}\right\}$ converges strongly to the unique solution of the variational inequality

$$
\left\langle(\gamma f-A) x^{*}, x-x^{*}\right\rangle \leq 0, \quad \forall x \in F(T)
$$


which is the optimality condition for the minimization problem

$$
\min _{x \in C} \frac{1}{2}\langle A x, x\rangle-h(x)
$$

where $h$ is a potential function for $\gamma f$ (i.e., $h^{\prime}(x)=\gamma f(x)$ for all $x \in H$ ).

In 2007, Takahashi and Takahashi [5] introduced an iterative scheme by the viscosity approximation method for finding a common element of the set of solutions of the EP and the set of fixed points of a nonexpansive mapping in a real Hilbert space. Let $S: C \rightarrow H$ be a nonexpansive mapping. Starting with arbitrary initial $x_{1} \in H$, define sequences $\left\{x_{n}\right\}$ and $\left\{u_{n}\right\}$ recursively by

$$
\left\{\begin{array}{l}
F\left(u_{n}, y\right)+\frac{1}{r_{n}}\left\langle y-u_{n}, u_{n}-x_{n}\right\rangle \geq 0, \quad \forall y \in C, \\
x_{n+1}=\alpha_{n} f\left(x_{n}\right)+\left(1-\alpha_{n}\right) S u_{n}, \quad \forall n \geq 1 .
\end{array}\right.
$$

They proved that under appropriate conditions imposed on $\left\{\alpha_{n}\right\}$ and $\left\{r_{n}\right\}$, the sequences $\left\{x_{n}\right\}$ and $\left\{u_{n}\right\}$ converge strongly to $x^{*} \in F(S) \cap \operatorname{EP}(F)$, where $x^{*}=P_{F(S) \cap E \mathrm{P}(F)} f\left(x^{*}\right)$.

Subsequently, Plubtieng and Punpaeng [19] introduced a general iterative process for finding a common element of the set of solutions of the EP and the set of fixed points of a nonexpansive mapping in a Hilbert space.

Let $S: H \rightarrow H$ be a nonexpansive mapping. Starting with an arbitrary $x_{1} \in H$, define sequences $\left\{x_{n}\right\}$ and $\left\{u_{n}\right\}$ by

$$
\left\{\begin{array}{l}
F\left(u_{n}, y\right)+\frac{1}{r_{n}}\left\langle y-u_{n}, u_{n}-x_{n}\right\rangle \geq 0, \quad \forall y \in C, \\
x_{n+1}=\alpha_{n} \gamma f\left(x_{n}\right)+\left(1-\alpha_{n} A\right) S u_{n}, \quad \forall n \geq 1 .
\end{array}\right.
$$

They proved that under appropriate conditions imposed on $\left\{\alpha_{n}\right\}$ and $\left\{r_{n}\right\}$, the sequence $\left\{x_{n}\right\}$ generated by (1.12) converges strongly to the unique solution $x^{*} \in F(S) \cap \operatorname{EP}(F)$ to the VIP

$$
\left\langle(\gamma f-A) x^{*}, x-x^{*}\right\rangle \leq 0, \quad \forall x \in F(S) \cap \operatorname{EP}(F)
$$

which is the optimality condition for the minimization problem

$$
\min _{x \in F(S) \cap \operatorname{EP}(F)} \frac{1}{2}\langle A x, x\rangle-h(x),
$$

where $h$ is a potential function for $\gamma f$ (i.e., $h^{\prime}(x)=\gamma f(x)$ for all $x \in H$ ).

In 2001, Yamada [20] introduced a hybrid steepest descent method for a nonexpansive mapping $T$ as follows:

$$
x_{n+1}=T x_{n}-\mu \lambda_{n} F\left(T x_{n}\right), \quad \forall n \geq 0,
$$

where $F$ is a $\kappa$-Lipschitzian and $\eta$-strongly monotone operator with constants $\kappa, \eta>0$ and $0<\mu<\frac{2 \eta}{\kappa^{2}}$. He proved that if $\left\{\lambda_{n}\right\}$ satisfies appropriate conditions, then the sequence $\left\{x_{n}\right\}$ generated by (1.13) converges strongly to the unique solution of the variational inequality

$$
\left\langle F x^{*}, x-x^{*}\right\rangle \leq 0, \quad \forall x \in F(T) .
$$


In 2010, Tian [21] combined the iterative method (1.10) with Yamada's method (1.13) and considered the following general viscosity-type iterative method:

$$
x_{n+1}=\alpha_{n} \gamma f\left(x_{n}\right)+\left(1-\alpha_{n} \mu F\right) T x_{n}, \quad \forall n \geq 0 .
$$

Then he proved that the sequence $\left\{x_{n}\right\}$ generated by (1.14) converges strongly to the unique solution of the variational inequality

$$
\left\langle(\gamma f-\mu F) x^{*}, x-x^{*}\right\rangle \leq 0, \quad \forall x \in F(T) .
$$

Recently, Ceng et al. [22] introduced implicit and explicit iterative schemes for finding the fixed points of a nonexpansive mapping $T$ on a nonempty, closed and convex subset $C$ in a real Hilbert space $H$ as follows:

$$
x_{t}=P_{C}\left[t \gamma V x_{t}+(1-t \mu F) T x_{t}\right]
$$

and

$$
x_{n+1}=P_{C}\left[\alpha_{n} \gamma V x_{n}+\left(1-\alpha_{n} \mu F\right) T x_{n}\right], \quad \forall n \geq 0,
$$

where $V$ is an $L$-Lipschitzian mapping with constant $L \geq 0$ and $F$ is a $\kappa$-Lipschitzian and $\eta$-strongly monotone operator with constants $\kappa, \eta>0$ and $0<\mu<\frac{2 \eta}{\kappa^{2}}$. Then they proved that the sequences generated by (1.15) and (1.16) converge strongly to the unique solution of the variational inequality

$$
\left\langle(\gamma V-\mu F) x^{*}, x-x^{*}\right\rangle \leq 0, \quad \forall x \in F(T) .
$$

Let $\left\{T_{n}\right\}_{n=1}^{\infty}$ be an infinite family of nonexpansive self-mappings on $C$ and $\left\{\lambda_{n}\right\}_{n=1}^{\infty}$ be a sequence of nonnegative numbers in $[0,1]$. For any $n \geq 1$, define a mapping $W_{n}$ of $C$ into itself as follows:

$$
\left\{\begin{array}{l}
U_{n, n+1}=I, \\
U_{n, n}=\lambda_{n} T_{n} U_{n, n+1}+\left(1-\lambda_{n}\right) I, \\
U_{n, n-1}=\lambda_{n-1} T_{n-1} U_{n, n}+\left(1-\lambda_{n-1}\right) I, \\
\ldots, \\
U_{n, k}=\lambda_{k} T_{k} U_{n, k+1}+\left(1-\lambda_{k}\right) I, \\
U_{n, k-1}=\lambda_{k-1} T_{k-1} U_{n, k}+\left(1-\lambda_{k-1}\right) I, \\
\cdots \\
U_{n, 2}=\lambda_{2} T_{2} U_{n, 3}+\left(1-\lambda_{2}\right) I, \\
W_{n}=U_{n, 1}=\lambda_{1} T_{1} U_{n, 2}+\left(1-\lambda_{1}\right) I .
\end{array}\right.
$$

Such a mapping $W_{n}$ is called the $W$-mapping generated by $T_{n}, T_{n-1}, \ldots, T_{1}$ and $\lambda_{n}, \lambda_{n-1}$, $\ldots, \lambda_{1}$.

Very recently, Chen [23] introduced and considered the following iterative scheme:

$$
x_{n+1}=P_{C}\left[\alpha_{n} \gamma f\left(x_{n}\right)+\left(1-\alpha_{n} A\right) W_{n} x_{n}\right], \quad \forall n \geq 0,
$$


where $A$ is a strongly positive bounded linear operator, $f$ is a contraction on $H$, and $W_{n}$ is defined as (1.17). He proved that the above sequence $\left\{x_{n}\right\}$ converges strongly to the unique solution of the variational inequality

$$
\left\langle(\gamma f-A) x^{*}, x-x^{*}\right\rangle \leq 0, \quad \forall x \in \bigcap_{n=1}^{\infty} F\left(T_{n}\right)
$$

which is the optimality condition for the minimization problem

$$
\min _{x \in \bigcap_{n=1}^{\infty} F\left(T_{n}\right)} \frac{1}{2}\langle A x, x\rangle-h(x),
$$

where $h$ is a potential function for $\gamma f$ (i.e., $h^{\prime}(x)=\gamma f(x)$ for all $x \in H$ ).

More recently, Rattanaseeha [7] introduced an iterative algorithm:

$$
\left\{\begin{array}{l}
x_{1} \in H, \quad \text { arbitrarily given, } \\
F\left(u_{n}, y\right)+\frac{1}{r_{n}}\left\langle y-u_{n}, u_{n}-x_{n}\right\rangle \geq 0, \quad \forall y \in C, \\
x_{n+1}=P_{C}\left[\alpha_{n} \gamma f\left(x_{n}\right)+\left(1-\alpha_{n} A\right) W_{n} x_{n}\right], \quad \forall n \geq 1,
\end{array}\right.
$$

where $A$ is a strongly positive bounded linear operator, $f$ is a contraction on $H$, and $W_{n}$ is defined as (1.17). He proved that the above sequence $\left\{x_{n}\right\}$ converges strongly to the unique solution of the variational inequality

$$
\left\langle(\gamma f-A) x^{*}, x-x^{*}\right\rangle \leq 0, \quad \forall x \in \bigcap_{n=1}^{\infty} F\left(T_{n}\right) \cap \mathrm{EP}(F) .
$$

Nowadays, Wang et al. [24] introduced an iterative algorithm:

$$
\left\{\begin{array}{l}
x_{1} \in H, \\
F\left(u_{n}, y\right)+\varphi(y)-\varphi\left(u_{n}\right)+\frac{1}{r_{n}}\left\langle y-u_{n}, u_{n}-x_{n}\right\rangle \geq 0, \quad \forall y \in C, \\
x_{n+1}=P_{c}\left[\alpha_{n} \gamma f\left(x_{n}\right)+\beta_{n} x_{n}+\left(\left(1-\beta_{n}\right) I-\alpha_{n} A\right) W_{n} u_{n}\right], \quad \forall n \geq 1,
\end{array}\right.
$$

where $A$ is a strongly positive bounded linear operator, $f$ is an $l$-Lipschitz continuous mapping, $\left\{W_{n}\right\}$ is defined by (1.17), and $G=P_{C}\left(I-\mu_{1} B_{1}\right) P_{C}\left(I-\mu_{2} B_{2}\right)$. They proved that the above sequence $\left\{x_{n}\right\}$ converges strongly to $x^{*} \in \Omega:=\bigcap_{n=1}^{\infty} F\left(T_{n}\right) \cap \operatorname{MEP}(F, \varphi) \cap \Gamma$, where $\Gamma$ is a fixed point set of the mapping $G=P_{C}\left(I-\mu_{1} B_{1}\right) P_{C}\left(I-\mu_{2} B_{2}\right)$, which is the unique solution of the VIP

$$
\left\langle(A-\gamma f) x^{*}, x^{*}-x\right\rangle \leq 0, \quad \forall x \in \Omega
$$

or, equivalently, the unique solution of the minimization problem

$$
\min _{x \in \Omega} \frac{1}{2}\langle A x, x\rangle-h(x)
$$

Our concern now is the following:

Question 1 Can Theorem 3.1 of Rattanaseeha [7], Theorem 3.1 of Wang et al. [24] and so on be extended from one mixed equilibrium problem to the convex combination of a finite family of the mixed equilibrium problems? 
Question 2 We know that GSEP (1.5) is more general than GSVI (1.6). What happens if GSVI (1.6) is replaced by GSEP (1.5)?

Question 3 We know that the $\eta$-strongly monotone and $L$-Lipschitz operator is more general than the strongly positive bounded linear operator. What happens if the strongly positive bounded linear operator is replaced by the $\eta$-strongly monotone and $L$-Lipschitz operator?

The purpose of this article is to give the affirmative answers to these questions mentioned above. Let $B_{i}: C \rightarrow H$ be $\zeta_{i}$-inverse strongly monotone for $i=1,2, B_{3}$ be a $\kappa$-Lipschitz and $\eta$-strongly monotone operator and $f: C \rightarrow H$ be an $l$-Lipschitz mapping on $H$. Motivated by the above facts, in this paper we propose and analyze the general iterative algorithm

$$
\left\{\begin{array}{l}
y_{n}=\lambda_{n} W_{n} G\left(\sum_{m=1}^{N} \beta_{n, m} u_{n, m}\right)+\left(1-\lambda_{n}\right)\left(\sum_{m=1}^{N} \beta_{n, m} u_{n, m}\right), \\
x_{n+1}=P_{C}\left[\alpha_{n} \gamma f\left(x_{n}\right)+\left(1-\alpha_{n} \mu B_{3}\right) W_{n} G y_{n}\right], \quad \forall n \geq 1,
\end{array}\right.
$$

where $\left\{u_{n, m}\right\}$ is such that

$$
F_{m}\left(u_{n, m}, y\right)+\varphi(y)-\varphi\left(u_{n, m}\right)+\frac{1}{r_{n, m}}\left\langle y-u_{n, m}, u_{n, m}-x_{n}\right\rangle \geq 0, \quad \forall y \in C,
$$

for each $1 \leq m \leq N, W_{n}$ is defined by (1.17) and $G=T_{\mu_{1}}^{\Theta_{1}}\left(I-\mu_{1} B_{1}\right) T_{\mu_{2}}^{\Theta_{2}}\left(I-\mu_{2} B_{2}\right)$, and $x_{0} \in C$ is an arbitrary initial point, for finding a common solution of a finite family of MEP (1.2), GSEP (1.5) and the fixed point problem of an infinite family of nonexpansive self-mappings $\left\{T_{n}\right\}_{n=1}^{\infty}$ on $C$. It is proven that under some mild conditions imposed on parameters, the sequence $\left\{x_{n}\right\}$ generated by (1.20) converges strongly to $x^{*} \in$ $\Omega:=\left(\bigcap_{n=1}^{\infty} F\left(T_{n}\right)\right) \cap\left(\bigcap_{m=1}^{N} \operatorname{MEP}\left(F_{m}, \varphi\right)\right) \cap \Gamma$, where $\Gamma$ is a fixed point set of the mapping $G=T_{\mu_{1}}^{\Theta_{1}}\left(I-\mu_{1} B_{1}\right) T_{\mu_{2}}^{\Theta_{2}}\left(I-\mu_{2} B_{2}\right)$, where $x^{*}$ is the unique solution of the variational inequality

$$
\left\langle\left(\gamma f-\mu B_{3}\right) x^{*}, z-x^{*}\right\rangle \leq 0, \quad \forall z \in \Omega
$$

Remark 1.4 Other results on the problem of finding solutions to equilibrium problems and fixed point problems of families of mappings with different approaches can be found in $[25,26]$.

\section{Preliminaries}

We indicate weak convergence and strong convergence by using the notation $\rightarrow$ and $\rightarrow$, respectively. A mapping $f: C \rightarrow H$ is called $l$-Lipschitz continuous if there exists a constant $l \geq 0$ such that

$$
\|f(x)-f(y)\| \leq l\|x-y\|, \quad \forall x, y \in C
$$

In particular, if $l=1$, then $f$ is called a nonexpansive mapping; if $l \in[0,1)$, then $f$ is a contraction. Recall that a mapping $T: H \rightarrow H$ is said to be a firmly nonexpansive mapping if

$$
\|T x-T y\|^{2} \leq\langle T x-T y, x-y\rangle, \quad \forall x, y \in H .
$$


The metric (or nearest point) projection from $H$ onto $C$ is the mapping $P_{C}: H \rightarrow C$ which assigns to each point $x \in H$ the unique point $P_{C} x \in C$ satisfying the property

$$
\left\|x-P_{C} x\right\|=\inf _{y \in C}\|x-y\|=: d(x, C)
$$

We need some facts and tools in a real Hilbert space $H$ which are listed as lemmas below.

Lemma 2.1 Let X be a real inner product space. Then there holds the following inequality:

$$
\|x+y\|^{2} \leq\|x\|^{2}+2\langle y, x+y\rangle, \quad \forall x, y \in X .
$$

Lemma 2.2 Let $H$ be a Hilbert space. Then the following equalities hold:

(a) $\|x-y\|^{2}=\|x\|^{2}-\|y\|^{2}-2\langle x-y, y\rangle$ for all $x, y \in H$;

(b) $\|\lambda x+\mu y\|^{2}=\lambda\|x\|^{2}+\mu\|y\|^{2}-\lambda \mu\|x-y\|^{2}$ for all $x, y \in H$ and $\lambda, \mu \in[0,1]$ with $\lambda+\mu=1$

(c) If $\left\{x_{n}\right\}$ is a sequence in $H$ such that $x_{n} \rightarrow x$, it follows that

$$
\limsup _{n \rightarrow \infty}\left\|x_{n}-y\right\|^{2}=\limsup _{n \rightarrow \infty}\left\|x_{n}-x\right\|^{2}+\|x-y\|^{2}, \quad \forall y \in H .
$$

We have the following crucial lemmas concerning the $W$-mappings defined by (1.17).

Lemma 2.3 (see [27, Lemma 3.2]) Let $\left\{T_{n}\right\}_{n=1}^{\infty}$ be a sequence of nonexpansive self-mappings on $C$ such that $\bigcap_{n=1}^{\infty} F\left(T_{n}\right) \neq \emptyset$, and let $\left\{\lambda_{n}\right\}$ be a sequence in $(0, b]$ for some $b \in(0,1)$. Then, for every $x \in C$ and $k \geq 1$, the limit $\lim _{n \rightarrow \infty} U_{n, k}$ exists, where $U_{n, k}$ is defined by (1.17).

Remark 2.1 (see [6, Remark 3.1]) It can be known from Lemma 2.3 that if $D$ is a nonempty bounded subset of $C$, then for $\epsilon>0$ there exists $n_{0} \geq k$ such that for all $n \geq n_{0}$,

$$
\sup _{x \in D}\left\|U_{n, k} x-U_{k} x\right\| \leq \epsilon
$$

Remark 2.2 (see [6, Remark 3.2]) Utilizing Lemma 2.3, we define a mapping $W: C \times C$ as follows:

$$
W x=\lim _{n \rightarrow \infty} W_{n} x=\lim _{n \rightarrow \infty} U_{n, 1} x, \quad \forall x \in C .
$$

Such $W$ is called the $W$-mapping generated by $T_{1}, T_{2}, \ldots$ and $\lambda_{1}, \lambda_{2}, \ldots$ Since $W_{n}$ is nonexpansive, $W: C \rightarrow C$ is also nonexpansive. Indeed, observe that for each $x, y \in C$,

$$
\|W x-W y\|=\lim _{n \rightarrow \infty}\left\|W_{n} x-W_{n} y\right\| \leq\|x-y\| .
$$

If $\left\{x_{n}\right\}$ is a bounded sequence in $C$, then we put $D=\left\{x_{n}: n \geq 1\right\}$. Hence, it is clear from Remark 2.1 that for arbitrary $\epsilon>0$ there exists $N_{0} \geq 1$ such that for all $n>N_{0}$,

$$
\left\|W_{n} x_{n}-W x_{n}\right\|=\left\|U_{n, 1} x_{n}-U_{1} x_{n}\right\| \leq \sup _{x \in D}\left\|U_{n, 1} x-U_{1} x\right\| \leq \epsilon
$$


This implies that

$$
\lim _{n \rightarrow \infty}\left\|W_{n} x_{n}-W x_{n}\right\|=0
$$

Lemma 2.4 (see [27, Lemma 3.3]) Let $\left\{T_{n}\right\}_{n=1}^{\infty}$ be a sequence of nonexpansive self-mappings on $C$ such that $\bigcap_{n=1}^{\infty} F\left(T_{n}\right) \neq \emptyset$, and let $\left\{\lambda_{n}\right\}$ be a sequence in $(0, b]$ for some $b \in(0,1)$. Then $F(W)=\bigcap_{n=1}^{\infty} F\left(T_{n}\right)$.

Lemma 2.5 (see [28, Demiclosedness principle]) Let C be a nonempty closed convex subset of a real Hilbert space $H$. Let $T$ be a nonexpansive self-mapping on $C$ with $F(T) \neq \emptyset$. Then $I-T$ is demiclosed. That is, whenever $\left\{x_{n}\right\}$ is a sequence in $C$ weakly converging to some $x \in C$ and the sequence $\left\{(I-T) x_{n}\right\}$ strongly converges to some $y$, it follows that $(I-T) x=y$. Here $I$ is the identity operator of $H$.

Lemma 2.6 Let $A: C \rightarrow H$ be a monotone mapping. In the context of the variational inequality problem, the characterization of the projection (see Proposition 1.1(i)) implies

$$
u \in \operatorname{VI}(C, A) \Leftrightarrow u=P_{C}(u-\lambda A u), \quad \forall \lambda>0 .
$$

Lemma 2.7 (see [29]) Assume that $\left\{a_{n}\right\}$ is a sequence of nonnegative real numbers such that

$$
a_{n+1} \leq\left(1-\gamma_{n}\right) a_{n}+\sigma_{n} \gamma_{n}, \quad \forall n \geq 1
$$

where $\gamma_{n}$ is a sequence in $[0,1]$ and $\sigma_{n}$ is a real sequence such that

(i) $\sum_{n=1}^{\infty} \gamma_{n}=\infty$;

(ii) $\lim \sup _{n \rightarrow \infty} \sigma_{n} \leq 0$ or $\sum_{n=1}^{\infty}\left|\sigma_{n} \gamma_{n}\right|<\infty$.

Then $\lim _{n \rightarrow \infty} a_{n}=0$.

Lemma 2.8 Each Hilbert space H satisfies Opial's condition, i.e., for the sequence $\left\{x_{n}\right\} \subset H$ with $x_{n} \rightarrow x$. Then the inequality

$$
\liminf _{n \rightarrow \infty}\left\|x_{n}-x\right\|<\liminf \left\|x_{n}-y\right\|
$$

holds for any $y \in H$ such that $y \neq x$.

\section{Main result}

We will introduce and analyze a general iterative algorithm for finding a common solution of a finite family of MEP (1.2), GSEP (1.5) and the fixed point problems of an infinite family of nonexpansive self-mappings $\left\{T_{n}\right\}_{n=1}^{\infty}$ on $C$. Under some appropriate conditions imposed on the parameter sequences, we will prove strong convergence of the proposed algorithm.

Theorem 3.1 Let $C$ be a nonempty closed convex subset of a Hilbert space $H$. Let $F_{m}$ be a sequence of bifunctions from $C \times C$ to $R$ satisfying (A1)-(A4), and let $\varphi: C \rightarrow R$ be a lower semicontinuous and convex function with restriction (B1) or (B2) for every $1 \leq m \leq N$, where $N$ denotes some positive integer. Let $\Theta_{1}, \Theta_{2}: C \times C \rightarrow R$ be two bifunctions satisfying (A1)-(A4), the mapping $B_{i}: C \rightarrow H$ be $\zeta_{i}$-inverse strongly monotone for $i=1,2$, $B_{3}$ be a $\kappa$-Lipschitz and $\eta$-strongly monotone operator with constants $\kappa, \eta>0$, and let 
$f: H \rightarrow H$ be an l-Lipschitz mapping with constant $l \geq 0$. Let $\left\{T_{n}\right\}_{n=1}^{\infty}$ be a sequence of nonexpansive mappings on $C$ and $\left\{\lambda_{n}\right\}$ be a sequence in $(0, b]$ for some $b \in(0,1)$. Suppose that $0<\mu<2 \eta / \kappa^{2}$ and $0<\gamma l<\tau$, where $\tau=1-\sqrt{1-\mu\left(2 \eta-\mu \kappa^{2}\right)}$. Assume that $\Omega:=\left(\bigcap_{n=1}^{\infty} F\left(T_{n}\right)\right) \cap\left(\bigcap_{m=1}^{N} \operatorname{MEP}\left(F_{m}, \varphi\right)\right) \cap \Gamma \neq \emptyset$, where $\Gamma$ is a fixed point set of the mapping $G=T_{\mu_{1}}^{\Theta_{1}}\left(I-\mu_{1} B_{1}\right) T_{\mu_{2}}^{\Theta_{2}}\left(I-\mu_{2} B_{2}\right)$ with $\mu_{i} \in\left(0,2 \zeta_{i}\right)$ for $i=1,2$. Let $\left\{\alpha_{n}\right\},\left\{\delta_{n}\right\},\left\{\beta_{n, 1}\right\}, \ldots$ and $\left\{\beta_{n, N}\right\}$ be sequences in $[0,1]$ and $\left\{r_{n, m}\right\}$ be a sequence in $(0, \infty)$ for every $1 \leq m \leq N$ such that:

(a) $\lim _{n \rightarrow \infty} \alpha_{n}=0, \sum_{n=1}^{\infty} \alpha_{n}=\infty$ and $\sum_{n=1}^{\infty}\left|\alpha_{n+1}-\alpha_{n}\right|<\infty$;

(b) $\sum_{m=1}^{N} \beta_{n, m}=1$ and $\sum_{n=1}^{\infty}\left|\beta_{n+1, m}-\beta_{n, m}\right|<\infty$ for each $1 \leq m \leq N$;

(c) $\lim _{n \rightarrow \infty} \delta_{n}=0$ and $\sum_{n=1}^{\infty}\left|\delta_{n+1}-\delta_{n}\right|<\infty$;

(d) $\liminf _{n \rightarrow \infty} r_{n, m}>0$ and $\sum_{n=1}^{\infty}\left|r_{n+1, m}-r_{n, m}\right|<\infty$ for each $1 \leq m \leq N$.

Given $x_{1} \in H$ arbitrarily, the sequence $\left\{x_{n}\right\}$ is generated iteratively by

$$
\left\{\begin{array}{l}
y_{n}=\delta_{n} W_{n} G\left(\sum_{m=1}^{N} \beta_{n, m} u_{n, m}\right)+\left(1-\delta_{n}\right)\left(\sum_{m=1}^{N} \beta_{n, m} u_{n, m}\right) \\
x_{n+1}=P_{C}\left[\alpha_{n} \gamma f\left(x_{n}\right)+\left(1-\alpha_{n} \mu B_{3}\right) W_{n} G y_{n}\right], \quad \forall n \geq 1
\end{array}\right.
$$

where $u_{n, m}$ is such that

$$
F_{m}\left(u_{n, m}, y\right)+\varphi(y)-\varphi\left(u_{n, m}\right)+\frac{1}{r_{n, m}}\left\langle y-u_{n, m}, u_{n, m}-x_{n}\right\rangle \geq 0, \quad \forall y \in C,
$$

for each $1 \leq m \leq N, W_{n}$ is defined by (1.17). Then the sequence $\left\{x_{n}\right\}$ defined by (3.1) converges strongly to $x^{*} \in \Omega$ as $n \rightarrow \infty$, where $x^{*}$ is the unique solution of the variational inequality

$$
\left\langle\left(\gamma f-\mu B_{3}\right) x^{*}, z-x^{*}\right\rangle \leq 0, \quad \forall z \in \Omega
$$

Proof Let $z_{n}=\sum_{m=1}^{N} \beta_{n, m} u_{n, m}$ in (3.1), then (3.1) reduces to

$$
\left\{\begin{array}{l}
z_{n}=\sum_{m=1}^{N} \beta_{n, m} u_{n, m}, \\
y_{n}=\delta_{n} W_{n} G z_{n}+\left(1-\delta_{n}\right) z_{n}, \\
x_{n+1}=P_{C}\left[\alpha_{n} \gamma f\left(x_{n}\right)+\left(1-\alpha_{n} \mu B_{3}\right) W_{n} G y_{n}\right], \quad \forall n \geq 1 .
\end{array}\right.
$$

We divide the proof into several steps.

Step 1. We show that $\left\{x_{n}\right\}$ is bounded. Indeed, take $p \in \Omega$ arbitrarily. Since $p=W_{n} p=$ $T_{r_{n, m}}^{\left(F_{m}, \varphi\right)} p=G p, B_{i}$ is $\zeta_{i}$-inverse-strongly monotone for $i=1,2$, by Remark 1.1 we deduce from $0 \leq \mu_{i} \leq 2 \zeta_{i}, i=1,2$ that for any $n \geq 1$,

$$
\begin{aligned}
\left\|G y_{n}-p\right\|^{2}= & \left\|T_{\mu_{1}}^{\Theta_{1}}\left(I-\mu_{1} B_{1}\right) T_{\mu_{2}}^{\Theta_{2}}\left(I-\mu_{2} B_{2}\right) y_{n}-T_{\mu_{1}}^{\Theta_{1}}\left(I-\mu_{1} B_{1}\right) T_{\mu_{2}}^{\Theta_{2}}\left(I-\mu_{2} B_{2}\right) p\right\|^{2} \\
\leq & \left\|\left(I-\mu_{1} B_{1}\right) T_{\mu_{2}}^{\Theta_{2}}\left(I-\mu_{2} B_{2}\right) y_{n}-\left(I-\mu_{1} B_{1}\right) T_{\mu_{2}}^{\Theta_{2}}\left(I-\mu_{2} B_{2}\right) p\right\|^{2} \\
= & \|\left[T_{\mu_{2}}^{\Theta_{2}}\left(I-\mu_{2} B_{2}\right) y_{n}-T_{\mu_{2}}^{\Theta_{2}}\left(I-\mu_{2} B_{2}\right) p\right] \\
& -\mu_{1}\left[B_{1} T_{\mu_{2}}^{\Theta_{2}}\left(I-\mu_{2} B_{2}\right) y_{n}-B_{1} T_{\mu_{2}}^{\Theta_{2}}\left(I-\mu_{2} B_{2}\right) p\right] \|^{2} \\
\leq & \left\|T_{\mu_{2}}^{\Theta_{2}}\left(I-\mu_{2} B_{2}\right) y_{n}-T_{\mu_{2}}^{\Theta_{2}}\left(I-\mu_{2} B_{2}\right) p\right\|^{2} \\
& +\mu_{1}\left(\mu_{1}-2 \zeta_{1}\right)\left\|B_{1} T_{\mu_{2}}^{\Theta_{2}}\left(I-\mu_{2} B_{2}\right) y_{n}-B_{1} T_{\mu_{2}}^{\Theta_{2}}\left(I-\mu_{2} B_{2}\right) p\right\|^{2} \\
\leq & \left\|T_{\mu_{2}}^{\Theta_{2}}\left(I-\mu_{2} B_{2}\right) y_{n}-T_{\mu_{2}}^{\Theta_{2}}\left(I-\mu_{2} B_{2}\right) p\right\|^{2}
\end{aligned}
$$




$$
\begin{aligned}
& \leq\left\|\left(I-\mu_{2} B_{2}\right) y_{n}-\left(I-\mu_{2} B_{2}\right) p\right\|^{2} \\
& =\left\|\left(y_{n}-p\right)-\mu_{2}\left(B_{2} y_{n}-B_{2} p\right)\right\|^{2} \\
& =\left\|y_{n}-p\right\|^{2}+\mu_{2}\left(\mu_{2}-2 \zeta_{2}\right)\left\|B_{2} y_{n}-B_{2} p\right\|^{2} \\
& \leq\left\|y_{n}-p\right\|^{2}=\left\|\delta_{n} W_{n} G z_{n}+\left(1-\delta_{n}\right) z_{n}-p\right\|^{2} \\
& \leq \delta_{n}\left\|W_{n} G z_{n}-p\right\|^{2}+\left(1-\delta_{n}\right)\left\|z_{n}-p\right\|^{2} \\
& \leq \delta_{n}\left\|G z_{n}-p\right\|^{2}+\left(1-\delta_{n}\right)\left\|z_{n}-p\right\|^{2} \leq \delta_{n}\left\|z_{n}-p\right\|^{2}+\left(1-\delta_{n}\right)\left\|z_{n}-p\right\|^{2} \\
& \leq\left\|z_{n}-p\right\|^{2}=\left\|\sum_{m=1}^{N} \beta_{n, m} u_{n, m}-p\right\|^{2} \leq \sum_{m=1}^{N} \beta_{n, m}\left\|u_{n, m}-p\right\|^{2} \\
& =\sum_{m=1}^{N} \beta_{n, m}\left\|T_{r_{n, m}}^{\left(F_{m}, \varphi\right)} x_{n}-T_{r_{n, m}}^{\left(F_{m}, \varphi\right)} p\right\|^{2} \leq \sum_{m=1}^{N} \beta_{n, m}\left\|x_{n}-p\right\|^{2}=\left\|x_{n}-p\right\|^{2} .
\end{aligned}
$$

(This shows that $G$ is nonexpansive.) It follows that

$$
\begin{aligned}
\left\|x_{n+1}-p\right\| & =\left\|P_{C}\left[\alpha_{n} \gamma f\left(x_{n}\right)+\left(1-\alpha_{n} \mu B_{3}\right) W_{n} G y_{n}\right]-p\right\| \\
& \leq\left\|\alpha_{n} \gamma f\left(x_{n}\right)+\left(1-\alpha_{n} \mu B_{3}\right) W_{n} G y_{n}-p\right\| \\
& =\left\|\alpha_{n}\left(\gamma f\left(x_{n}\right)-\mu B_{3} p\right)+\left(1-\alpha_{n} \mu B_{3}\right) W_{n} G y_{n}-\left(1-\alpha_{n} \mu B_{3}\right) p\right\| \\
& \leq \alpha_{n} \gamma l\left\|x_{n}-p\right\|+\alpha_{n}\left\|\left(\gamma f-\mu B_{3}\right) p\right\|+\left(1-\alpha_{n} \tau\right)\left\|W_{n} G y_{n}-p\right\| \\
& \leq \alpha_{n} \gamma l\left\|x_{n}-p\right\|+\alpha_{n}\left\|\left(\gamma f-\mu B_{3}\right) p\right\|+\left(1-\alpha_{n} \tau\right)\left\|G y_{n}-p\right\| \\
& \leq \alpha_{n} \gamma l\left\|x_{n}-p\right\|+\alpha_{n}\left\|\left(\gamma f-\mu B_{3}\right) p\right\|+\left(1-\alpha_{n} \tau\right)\left\|x_{n}-p\right\| \\
& =\left(1-\alpha_{n}(\tau-\gamma l)\right)\left\|x_{n}-p\right\|+\alpha_{n}\left\|\left(\gamma f-\mu B_{3}\right) p\right\| \\
& \leq \max \left\{\left\|x_{n}-p\right\|, \frac{\left\|\left(\gamma f-\mu B_{3}\right) p\right\|}{\tau-\gamma l}\right\} .
\end{aligned}
$$

By induction, we get

$$
\left\|x_{n}-p\right\| \leq \max \left\{\left\|x_{0}-p\right\|, \frac{\left\|\left(\gamma f-\mu B_{3}\right) p\right\|}{\tau-\gamma l}\right\}, \quad \forall n \geq 0
$$

Therefore, $\left\{x_{n}\right\}$ is bounded and so are the sequences $\left\{u_{n, m}\right\},\left\{z_{n}\right\},\left\{y_{n}\right\},\left\{f\left(x_{n}\right)\right\}$ and $\left\{W_{n} G y_{n}\right\}$. Without loss of generality, suppose that there exists a bounded subset $K \subset C$ such that

$$
x_{n}, u_{n, m}, z_{n}, y_{n}, W_{n} G x_{n}, W_{n} G z_{n}, W_{n} G y_{n} \in K, \quad \forall n \geq 1
$$

Step 2. Show that $\left\|x_{n+1}-x_{n}\right\| \rightarrow 0$ as $n \rightarrow \infty$.

First, we estimate $\left\|u_{n+1, m}-u_{n, m}\right\|$. Taking into account that $\liminf _{n \rightarrow \infty} r_{n, m}>0$, we may assume, without loss of generality, that $r_{n, m} \subset[\epsilon, \infty)$ for some $\epsilon>0$, for every $1 \leq m \leq N$. Utilizing Remark 1.1, we get

$$
\begin{aligned}
\left\|u_{n+1, m}-u_{n, m}\right\| & =\left\|T_{r_{n+1, m}}^{\left(F_{m}, \varphi\right)} x_{n+1}-T_{r_{n, m}}^{\left(F_{m}, \varphi\right)} x_{n}\right\| \\
& \leq\left\|T_{r_{n+1, m}}^{\left(F_{m}, \varphi\right)} x_{n+1}-T_{r_{n+1, m}}^{\left(F_{m}, \varphi\right)} x_{n}\right\|+\left\|T_{r_{n+1, m}}^{\left(F_{m}, \varphi\right)} x_{n}-T_{\left.r_{n, m}, \varphi\right)}^{\left(F_{m}, \varphi\right)} x_{n}\right\|
\end{aligned}
$$




$$
\begin{aligned}
& \leq\left\|x_{n+1}-x_{n}\right\|+\frac{\left|r_{n+1, m}-r_{n, m}\right|}{r_{n+1, m}}\left\|T_{r_{n+1, m}}^{\left(F_{m}, \varphi\right)} x_{n}-x_{n}\right\| \\
& \leq\left\|x_{n+1}-x_{n}\right\|+\frac{\left|r_{n+1, m}-r_{n, m}\right|}{\epsilon}\left\|T_{r_{n+1, m}}^{\left(F_{m}, \varphi\right)} x_{n}-x_{n}\right\| \\
& \leq\left\|x_{n+1}-x_{n}\right\|+M\left|r_{n+1, m}-r_{n, m}\right|,
\end{aligned}
$$

where $\sup _{n \geq 1}\left\{\frac{1}{\epsilon}\left\|T_{r_{n+1, m}}^{\left(F_{m}, \varphi\right)} x_{n}-x_{n}\right\|\right\} \leq M$ for some $M>0$. Next, we estimate $\left\|z_{n+1}-z_{n}\right\|$.

$$
\begin{aligned}
\left\|z_{n+1}-z_{n}\right\| & =\left\|\sum_{m=1}^{N} \beta_{n+1, m} u_{n+1, m}-\sum_{m=1}^{N} \beta_{n, m} u_{n, m}\right\| \\
& =\left\|\sum_{m=1}^{N}\left(\beta_{n+1, m} u_{n+1, m}-\beta_{n, m} u_{n, m}\right)\right\| \\
& \leq \sum_{m=1}^{N}\left(\left\|\beta_{n+1, m} u_{n+1, m}-\beta_{n, m} u_{n+1, m}\right\|\right)+\sum_{m=1}^{N}\left(\left\|\beta_{n, m} u_{n+1, m}-\beta_{n, m} u_{n, m}\right\|\right) \\
& \leq \sum_{m=1}^{N}\left(\left|\beta_{n+1, m}-\beta_{n, m}\right|\left\|u_{n+1, m}\right\|\right)+\sum_{m=1}^{N} \beta_{n, m}\left\|u_{n+1, m}-u_{n, m}\right\| \\
& \leq \sum_{m=1}^{N}\left(\left|\beta_{n+1, m}-\beta_{n, m}\right|\left\|u_{n+1, m}\right\|\right)+\sum_{m=1}^{N} \beta_{n, m}\left(\left\|x_{n+1}-x_{n}\right\|+M\left|r_{n+1, m}-r_{n, m}\right|\right) \\
& \leq\left\|x_{n+1}-x_{n}\right\|+\sum_{m=1}^{N} \beta_{n, m} M\left|r_{n+1, m}-r_{n, m}\right|+\left\|u_{n+1, m}\right\| \\
& \leq\left\|x_{n+1}-x_{n}\right\|+M \sum_{m=1}^{N}\left|r_{n+1, m}-r_{n, m}\right|+M_{0} \sum_{m=1}^{N}\left|\beta_{n+1, m}-\beta_{n, m}\right|
\end{aligned}
$$

where $M_{0}=\sum_{m=1}^{N}\left\|u_{n+1, m}\right\|$.

On the other hand, from (1.17), since $W_{n}, T_{n}$ and $U_{n, i}$ are all nonexpansive, we have

$$
\begin{aligned}
\left\|W_{n+1} G z_{n}-W_{n} G z_{n}\right\|= & \left\|\lambda_{1} T_{1} U_{n+1,2} G z_{n}-\lambda_{1} T_{1} U_{n, 2} G z_{n}\right\| \\
\leq & \lambda_{1}\left\|U_{n+1,2} G z_{n}-U_{n, 2} G z_{n}\right\| \\
= & \lambda_{1}\left\|\lambda_{2} T_{2} U_{n+1,3} G z_{n}-\lambda_{2} T_{2} U_{n, 3} G z_{n}\right\| \\
\leq & \lambda_{1} \lambda_{2}\left\|U_{n+1,3} G z_{n}-U_{n, 3} G z_{n}\right\| \\
& \ldots \\
\leq & \lambda_{1} \lambda_{2} \cdots \lambda_{n}\left\|U_{n+1, n+1} G z_{n}-U_{n, n+1} G z_{n}\right\| \\
\leq & M_{1} \prod_{i=1}^{n} \lambda_{i},
\end{aligned}
$$

where $\sup _{n \geq 1}\left\{\left\|U_{n+1, n+1} G z_{n}\right\|+\left\|U_{n, n+1} G z_{n}\right\|\right\} \leq M_{1}$ for some $M_{1}>0$. Hence, we have

$$
\begin{aligned}
& \left\|W_{n+1} G z_{n+1}-W_{n} G z_{n}\right\| \\
& \quad \leq\left\|W_{n+1} G z_{n+1}-W_{n+1} G z_{n}\right\|+\left\|W_{n+1} G z_{n}-W_{n} G z_{n}\right\|
\end{aligned}
$$




$$
\begin{aligned}
& \leq\left\|z_{n+1}-z_{n}\right\|+M_{1} \prod_{i=1}^{n} \lambda_{i} \\
& \leq\left\|x_{n+1}-x_{n}\right\|+M \sum_{m=1}^{N}\left|r_{n+1, m}-r_{n, m}\right|+M_{0} \sum_{m=1}^{N}\left|\beta_{n+1, m}-\beta_{n, m}\right|+M_{1} \prod_{i=1}^{n} \lambda_{i} .
\end{aligned}
$$

Putting (3.9) and (3.7) into (3.3), we have

$$
\begin{aligned}
& \left\|y_{n+1}-y_{n}\right\| \\
& \leq \delta_{n+1}\left\|W_{n+1} G z_{n+1}-W_{n} G z_{n}\right\|+\left(1-\delta_{n+1}\right)\left\|z_{n+1}-z_{n}\right\|+\left|\delta_{n+1}-\delta_{n}\right|\left\|W_{n} G z_{n}-z_{n}\right\| \\
& \leq \delta_{n+1}\left(\left\|z_{n+1}-z_{n}\right\|+M_{1} \prod_{i=1}^{n} \lambda_{i}\right)+\left(1-\delta_{n+1}\right)\left\|z_{n+1}-z_{n}\right\|+\left|\delta_{n+1}-\delta_{n}\right|\left\|W_{n} G z_{n}-z_{n}\right\| \\
& \leq\left\|z_{n+1}-z_{n}\right\|+\delta_{n+1} M_{1} \prod_{i=1}^{n} \lambda_{i}+\left|\delta_{n+1}-\delta_{n}\right|\left\|W_{n} G z_{n}-z_{n}\right\| \\
& \leq\left\|x_{n+1}-x_{n}\right\|+M \sum_{m=1}^{N}\left|r_{n+1, m}-r_{n, m}\right|+M_{0} \sum_{m=1}^{N}\left|\beta_{n+1, m}-\beta_{n, m}\right| \\
& \quad+\delta_{n+1} M_{1} \prod_{i=1}^{n} \lambda_{i}+\left|\delta_{n+1}-\delta_{n}\right|\left\|W_{n} G z_{n}-z_{n}\right\| .
\end{aligned}
$$

Similarly to (3.8), we have

$$
\begin{aligned}
\left\|W_{n+1} G y_{n}-W_{n} G y_{n}\right\|= & \left\|\lambda_{1} T_{1} U_{n+1,2} G y_{n}-\lambda_{1} T_{1} U_{n, 2} G y_{n}\right\| \\
\leq & \lambda_{1}\left\|U_{n+1,2} G y_{n}-U_{n, 2} G y_{n}\right\| \\
= & \lambda_{1}\left\|\lambda_{2} T_{2} U_{n+1,3} G y_{n}-\lambda_{2} T_{2} U_{n, 3} G y_{n}\right\| \\
\leq & \lambda_{1} \lambda_{2}\left\|U_{n+1,3} G y_{n}-U_{n, 3} G y_{n}\right\| \\
& \ldots \\
\leq & \lambda_{1} \lambda_{2} \cdots \lambda_{n}\left\|U_{n+1, n+1} G y_{n}-U_{n, n+1} G y_{n}\right\| \\
\leq & M_{2} \prod_{i=1}^{n} \lambda_{i}
\end{aligned}
$$

where $\sup _{n \geq 1}\left\{\left\|U_{n+1, n+1} G y_{n}\right\|+\left\|U_{n, n+1} G y_{n}\right\|\right\} \leq M_{2}$ for some $M_{2}>0$. Then we have

$$
\begin{aligned}
& \left\|W_{n+1} G y_{n+1}-W_{n} G y_{n}\right\| \\
& \leq\left\|W_{n+1} G y_{n+1}-W_{n+1} G y_{n}\right\|+\left\|W_{n+1} G y_{n}-W_{n} G y_{n}\right\| \\
& \leq\left\|y_{n+1}-y_{n}\right\|+M_{2} \prod_{i=1}^{n} \lambda_{i} \\
& \leq\left\|x_{n+1}-x_{n}\right\|+M \sum_{m=1}^{N}\left|r_{n+1, m}-r_{n, m}\right|+M_{0} \sum_{m=1}^{N}\left|\beta_{n+1, m}-\beta_{n, m}\right| \\
& \quad+\delta_{n+1} M_{1} \prod_{i=1}^{n} \lambda_{i}+\left|\delta_{n+1}-\delta_{n}\right|\left\|W_{n} G z_{n}-z_{n}\right\|+M_{2} \prod_{i=1}^{n} \lambda_{i} .
\end{aligned}
$$


Hence, it follows from (3.3)-(3.12) that

$$
\begin{aligned}
\| x_{n+2} & -x_{n+1} \| \\
= & \| P_{C}\left[\alpha_{n+1} \gamma f\left(x_{n+1}\right)+\left(1-\alpha_{n+1} \mu B_{3}\right) W_{n+1} G y_{n+1}\right] \\
& -P_{C}\left[\alpha_{n} \gamma f\left(x_{n}\right)+\left(1-\alpha_{n} \mu B_{3}\right) W_{n} G y_{n}\right] \| \\
\leq & \left\|\left[\alpha_{n+1} \gamma f\left(x_{n+1}\right)+\left(1-\alpha_{n+1} \mu B_{3}\right) W_{n+1} G y_{n+1}\right]-\left[\alpha_{n} \gamma f\left(x_{n}\right)+\left(1-\alpha_{n} \mu B_{3}\right) W_{n} G y_{n}\right]\right\| \\
\leq & \| \alpha_{n} \gamma\left(f\left(x_{n+1}\right)-f\left(x_{n}\right)\right)+\gamma\left(\alpha_{n+1}-\alpha_{n}\right) f\left(x_{n+1}\right) \\
& +\left(1-\alpha_{n} \mu B_{3}\right)\left(W_{n+1} G y_{n+1}-W_{n} G y_{n}\right)+\mu\left(\alpha_{n}-\alpha_{n+1}\right) B_{3} W_{n+1} G y_{n+1} \| \\
\leq & \alpha_{n} \gamma l\left\|x_{n+1}-x_{n}\right\|+\left|\alpha_{n+1}-\alpha_{n}\right|\left(\gamma\left\|f\left(x_{n+1}\right)\right\|+\mu\left\|B_{3} W_{n+1} G y_{n+1}\right\|\right) \\
& +\left(1-\alpha_{n} \tau\right)\left\|W_{n+1} G y_{n+1}-W_{n} G y_{n}\right\| \\
\leq & \left(1-\alpha_{n}(\tau-\gamma l)\right)\left\|x_{n+1}-x_{n}\right\|+\left|\alpha_{n+1}-\alpha_{n}\right|\left(\gamma\left\|f\left(x_{n+1}\right)\right\|+\mu\left\|B_{3} W_{n+1} G y_{n+1}\right\|\right) \\
& +\left(1-\alpha_{n} \tau\right)\left(M \sum_{m=1}^{N}\left|r_{n+1, m}-r_{n, m}\right|+M_{0} \sum_{m=1}^{N}\left|\beta_{n+1, m}-\beta_{n, m}\right|+\delta_{n+1} M_{1} \prod_{i=1}^{n} \lambda_{i}\right. \\
& \left.+\sum_{m=1}^{N}\left|\beta_{n+1, m}-\beta_{n, m}\right|+\left|\delta_{n+1}-\delta_{n}\right|+b^{n}\right), \\
& \left.+\left|\delta_{n+1}-\delta_{n}\right|\left\|W_{n} G z_{n}-z_{n}\right\|+M_{2} \prod_{i=1}^{n} \lambda_{i}\right) \\
\leq & \left(1-\alpha_{n}(\tau-\gamma l)\right)\left\|x_{n+1}-x_{n}\right\|+M_{3}\left(\left|\alpha_{n+1}-\alpha_{n}\right|+\sum_{m=1}^{N}\left|r_{n+1, m}-r_{n, m}\right|\right. \\
& N .13) \\
& +(\tau)
\end{aligned}
$$

where $\sup _{n \geq 1}\left\{\gamma\left\|f\left(x_{n+1}\right)\right\|+\mu\left\|B_{3} W_{n+1} G y_{n+1}\right\|+M+M_{0}+\left\|W_{n} G z_{n}-z_{n}\right\|+\delta_{n+1} M_{1}+M_{2}\right\} \leq M_{3}$ for some $M_{3}>0$. Noticing conditions (a), (b), (c), (d) and Lemma 2.7, we get $\left\|x_{n+1}-x_{n}\right\| \rightarrow$ 0 as $n \rightarrow \infty$.

Step 3. We show that

$$
\begin{aligned}
& \lim _{n \rightarrow \infty}\left\|y_{n}-G y_{n}\right\|=0, \\
& \lim _{n \rightarrow \infty}\left\|x_{n}-u_{n, m}\right\|=0, \quad \forall 1 \leq m \leq N, \\
& \lim _{n \rightarrow \infty}\left\|x_{n}-W G x_{n}\right\|=0
\end{aligned}
$$

First, we show $\lim _{n \rightarrow \infty}\left\|y_{n}-G y_{n}\right\|=0$. Indeed, for simplicity, we write $\tilde{y}_{n}=T_{\mu_{2}}^{\Theta_{2}}(I-$ $\left.\mu_{2} B_{2}\right) y_{n}, \tilde{p}=T_{\mu_{2}}^{\Theta_{2}}\left(I-\mu_{2} B_{2}\right) p, w_{n}=T_{\mu_{1}}^{\Theta_{1}}\left(I-\mu_{1} B_{1}\right) \tilde{y}_{n}$. Then $w_{n}=G y_{n}$ and $p=G p$. Similar to the proof of (3.4), we get

$$
\left\|G y_{n}-p\right\|^{2} \leq\left\|y_{n}-p\right\|^{2}+\mu_{2}\left(\mu_{2}-2 \zeta_{2}\right)\left\|B_{2} y_{n}-B_{2} p\right\|^{2}+\mu_{1}\left(\mu_{1}-2 \zeta_{1}\right)\left\|B \tilde{y}_{n}-B_{1} \tilde{p}\right\|^{2}
$$

From (3.3), (3.4), (3.17), we obtain that for $p \in \Omega$,

$$
\begin{aligned}
& \left\|x_{n+1}-p\right\|^{2} \\
& \quad \leq\left\|\alpha_{n} \gamma f\left(x_{n}\right)+\left(1-\alpha_{n} \mu B_{3}\right) W_{n} G y_{n}-p\right\|^{2}
\end{aligned}
$$




$$
\begin{aligned}
= & \left\|\alpha_{n}\left(\gamma f\left(x_{n}\right)-\mu B_{3} W_{n} G y_{n}\right)+W_{n} G y_{n}-p\right\|^{2} \\
= & \left\|W_{n} G y_{n}-p\right\|^{2}+2 \alpha_{n}\left\langle\gamma f\left(x_{n}\right)-\mu B_{3} W_{n} G y_{n}, W_{n} G y_{n}-p\right\rangle \\
& +\alpha_{n}{ }^{2}\left\|\gamma f\left(x_{n}\right)-\mu B_{3} W_{n} G y_{n}\right\|^{2} \\
\leq & \left\|G y_{n}-p\right\|^{2}+\alpha_{n}\left\|\gamma f\left(x_{n}\right)-\mu B_{3} W_{n} G y_{n}\right\| \\
& \quad \times\left[2\left\|W_{n} G y_{n}-p\right\|+\alpha_{n}\left\|\gamma f\left(x_{n}\right)-\mu B_{3} W_{n} G y_{n}\right\|\right] \\
\leq & \left\|y_{n}-p\right\|^{2}+\mu_{2}\left(\mu_{2}-2 \zeta_{2}\right)\left\|B_{2} y_{n}-B_{2} p\right\|^{2}+\mu_{1}\left(\mu_{1}-2 \zeta_{1}\right)\left\|B \tilde{y}_{n}-B_{1} \tilde{p}\right\|^{2} \\
& +\alpha_{n}\left\|\gamma f\left(x_{n}\right)-\mu B_{3} W_{n} G y_{n}\right\|\left[2\left\|W_{n} G y_{n}-p\right\|+\alpha_{n}\left\|\gamma f\left(x_{n}\right)-\mu B_{3} W_{n} G y_{n}\right\|\right] \\
\leq & \left\|x_{n}-p\right\|^{2}+\mu_{2}\left(\mu_{2}-2 \zeta_{2}\right)\left\|B_{2} y_{n}-B_{2} p\right\|^{2}+\mu_{1}\left(\mu_{1}-2 \zeta_{1}\right)\left\|B \tilde{y}_{n}-B_{1} \tilde{p}\right\|^{2} \\
& +\alpha_{n}\left\|\gamma f\left(x_{n}\right)-\mu B_{3} W_{n} G y_{n}\right\|\left[2\left\|W_{n} G y_{n}-p\right\|+\alpha_{n}\left\|\gamma f\left(x_{n}\right)-\mu B_{3} W_{n} G y_{n}\right\|\right],
\end{aligned}
$$

which immediately implies that

$$
\begin{aligned}
& \mu_{2}\left(2 \zeta_{2}-\mu_{2}\right)\left\|B_{2} y_{n}-B_{2} p\right\|^{2}+\mu_{1}\left(2 \zeta_{1}-\mu_{1}\right)\left\|B_{1} \tilde{y}_{n}-B_{1} \tilde{p}\right\|^{2} \\
& \leq \| \\
& \quad \times x_{n}-p\left\|^{2}-\right\| x_{n+1}-p\left\|^{2}+\alpha_{n}\right\| \gamma f\left(x_{n}\right)-\mu B_{3} W_{n} G y_{n} \| \\
& \quad \times\left[2\left\|W_{n} G y_{n}-p\right\|+\alpha_{n}\left\|\gamma f\left(x_{n}\right)-\mu B_{3} W_{n} G y_{n}\right\|\right] \\
& \leq \\
& \quad\left\|x_{n}-x_{n-1}\right\|\left(\left\|x_{n}-p\right\|+\left\|x_{n+1}-p\right\|\right) \\
& \quad+\alpha_{n}\left\|\gamma f\left(x_{n}\right)-\mu B_{3} W_{n} G y_{n}\right\|\left[2\left\|W_{n} G y_{n}-p\right\|+\alpha_{n}\left\|\gamma f\left(x_{n}\right)-\mu B_{3} W_{n} G y_{n}\right\|\right] .
\end{aligned}
$$

Since $\lim _{n \rightarrow \infty} \alpha_{n}=0, \lim _{n \rightarrow \infty}\left\|x_{n}-x_{n+1}\right\|=0$ and $\mu_{i} \in\left(0,2 \zeta_{i}\right), i=1,2$, we deduce from the boundedness of $\left\{x_{n}\right\}, f\left(x_{n}\right)$ and $\left\{W_{n} G y_{n}\right\}$ that

$$
\lim _{n \rightarrow \infty}\left\|B_{2} y_{n}-B_{2} p\right\|=0, \quad \lim _{n \rightarrow \infty}\left\|B_{1} \tilde{y}_{n}-B_{1} \tilde{p}\right\|=0
$$

Also, in terms of the firm nonexpansivity of $T_{\mu_{1}}^{\Theta_{1}}, T_{\mu_{2}}^{\Theta_{2}}$, we obtain from $\mu_{i} \in\left(0,2 \zeta_{i}\right), i=1,2$, that

$$
\begin{aligned}
\left\|\tilde{y}_{n}-\tilde{p}\right\|^{2}= & \left\|T_{\mu_{2}}^{\Theta_{2}}\left(I-\mu_{2} B_{2}\right) y_{n}-T_{\mu_{2}}^{\Theta_{2}}\left(I-\mu_{2} B_{2}\right) p\right\|^{2} \\
\leq & \left\langle\left(I-\mu_{2} B_{2}\right) y_{n}-\left(I-\mu_{2} B_{2}\right) p, \tilde{y}_{n}-\tilde{p}\right\rangle \\
= & \frac{1}{2}\left[\left\|\left(I-\mu_{2} B_{2}\right) y_{n}-\left(I-\mu_{2} B_{2}\right) p\right\|^{2}+\left\|\tilde{y}_{n}-\tilde{p}\right\|^{2}\right. \\
& \left.-\left\|\left(I-\mu_{2} B_{2}\right) y_{n}-\left(I-\mu_{2} B_{2}\right) p-\left(\tilde{y}_{n}-\tilde{p}\right)\right\|^{2}\right] \\
\leq & \frac{1}{2}\left[\left\|y_{n}-p\right\|^{2}+\left\|\tilde{y}_{n}-\tilde{p}\right\|^{2}-\left\|\left(y_{n}-\tilde{y}_{n}\right)-\mu_{2}\left(B_{2} y_{n}-B_{2} p\right)-(p-\tilde{p})\right\|^{2}\right] \\
\leq & \frac{1}{2}\left[\left\|x_{n}-p\right\|^{2}+\left\|\tilde{y}_{n}-\tilde{p}\right\|^{2}-\left\|\left(y_{n}-\tilde{y}_{n}\right)-(p-\tilde{p})\right\|^{2}\right. \\
& \left.+2 \mu_{2}\left\langle\left(y_{n}-\tilde{y}_{n}\right)-(p-\tilde{p}), B_{2} y_{n}-B_{2} p\right\rangle\right]
\end{aligned}
$$

and

$$
\begin{aligned}
\left\|w_{n}-p\right\|^{2} & =\left\|T_{\mu_{1}}^{\Theta_{1}}\left(I-\mu_{1} B_{1}\right) \tilde{y}_{n}-T_{\mu_{1}}^{\Theta_{1}}\left(I-\mu_{1} B_{1}\right) \tilde{p}\right\|^{2} \\
& \leq\left\langle\left(I-\mu_{1} B_{1}\right) \tilde{y}_{n}-\left(I-\mu_{1} B_{1}\right) \tilde{p}, w_{n}-p\right\rangle
\end{aligned}
$$




$$
\begin{aligned}
= & \frac{1}{2}\left[\left\|\left(I-\mu_{1} B_{1}\right) \tilde{y}_{n}-\left(I-\mu_{1} B_{1}\right) \tilde{p}\right\|^{2}+\left\|w_{n}-p\right\|^{2}\right. \\
& \left.-\left\|\left(I-\mu_{1} B_{1}\right) \tilde{y}_{n}-\left(I-\mu_{1} B_{1}\right) \tilde{p}-\left(w_{n}-p\right)\right\|^{2}\right] \\
\leq & \frac{1}{2}\left[\left\|\tilde{y}_{n}-\tilde{p}\right\|^{2}+\left\|w_{n}-p\right\|^{2}-\left\|\left(\tilde{y}_{n}-w_{n}\right)+(p-\tilde{p})\right\|^{2}\right. \\
& \left.-2 \mu_{1}\left\langle B_{1} \tilde{y}_{n}-B_{1} \tilde{p},\left(\tilde{y}_{n}-w_{n}\right)+(p-\tilde{p})\right\rangle-\mu_{1}^{2}\left\|B_{1} \tilde{y}_{n}-B_{1} \tilde{p}\right\|^{2}\right] \\
\leq & \frac{1}{2}\left[\left\|x_{n}-p\right\|^{2}+\left\|w_{n}-p\right\|^{2}-\left\|\left(\tilde{y}_{n}-w_{n}\right)+(p-\tilde{p})\right\|^{2}\right. \\
& \left.+2 \mu_{1}\left\langle B_{1} \tilde{y}_{n}-B_{1} \tilde{p},\left(\tilde{y}_{n}-w_{n}\right)+(p-\tilde{p})\right\rangle\right] .
\end{aligned}
$$

Thus, we have

$$
\begin{aligned}
\left\|\tilde{y}_{n}-\tilde{p}\right\|^{2} \leq & \left\|x_{n}-p\right\|^{2}-\left\|\left(y_{n}-\tilde{y}_{n}\right)-(p-\tilde{p})\right\|^{2} \\
& +2 \mu_{2}\left\langle\left(y_{n}-\tilde{y}_{n}\right)-(p-\tilde{p}), B_{2} y_{n}-B_{2} p\right\rangle
\end{aligned}
$$

and

$$
\begin{aligned}
\left\|w_{n}-p\right\|^{2} \leq & \left\|x_{n}-p\right\|^{2}-\left\|\left(\tilde{y}_{n}-w_{n}\right)+(p-\tilde{p})\right\|^{2} \\
& +2 \mu_{1}\left\langle B_{1} \tilde{y}_{n}-B_{1} \tilde{p},\left(\tilde{y}_{n}-w_{n}\right)+(p-\tilde{p})\right\rangle .
\end{aligned}
$$

Consequently, it follows from (3.4), (3.18) and (3.20) that

$$
\begin{aligned}
&\left\|x_{n+1}-p\right\|^{2} \\
& \leq\left\|G y_{n}-p\right\|^{2}+\alpha_{n}\left\|\gamma f\left(x_{n}\right)-\mu B_{3} W_{n} G y_{n}\right\| \\
& \times\left[2\left\|W_{n} G y_{n}-p\right\|+\alpha_{n}\left\|\gamma f\left(x_{n}\right)-\mu B_{3} W_{n} G y_{n}\right\|\right] \\
& \leq\left\|\tilde{y}_{n}-\tilde{p}\right\|^{2}+\alpha_{n}\left\|\gamma f\left(x_{n}\right)-\mu B_{3} W_{n} G y_{n}\right\| \\
& \times\left[2\left\|W_{n} G y_{n}-p\right\|+\alpha_{n}\left\|\gamma f\left(x_{n}\right)-\mu B_{3} W_{n} G y_{n}\right\|\right] \\
& \leq\left\|x_{n}-p\right\|^{2}-\left\|\left(y_{n}-\tilde{y}_{n}\right)-(p-\tilde{p})\right\|^{2}+2 \mu_{2}\left\langle\left(y_{n}-\tilde{y}_{n}\right)-(p-\tilde{p}), B_{2} y_{n}-B_{2} p\right\rangle \\
&+\alpha_{n}\left\|\gamma f\left(x_{n}\right)-\mu B_{3} W_{n} G y_{n}\right\|\left[2\left\|W_{n} G y_{n}-p\right\|+\alpha_{n}\left\|\gamma f\left(x_{n}\right)-\mu B_{3} W_{n} G y_{n}\right\|\right],
\end{aligned}
$$

which yields

$$
\begin{aligned}
&\left\|\left(y_{n}-\tilde{y}_{n}\right)-(p-\tilde{p})\right\|^{2} \\
& \leq \leq\left\|x_{n}-p\right\|^{2}-\left\|x_{n+1}-p\right\|^{2}+2 \mu_{2}\left\|\left(y_{n}-\tilde{y}_{n}\right)-(p-\tilde{p})\right\|\left\|B_{2} y_{n}-B_{2} p\right\| \\
& \quad+\alpha_{n}\left\|\gamma f\left(x_{n}\right)-\mu B_{3} W_{n} G y_{n}\right\|\left[2\left\|W_{n} G y_{n}-p\right\|+\alpha_{n}\left\|\gamma f\left(x_{n}\right)-\mu B_{3} W_{n} G y_{n}\right\|\right] \\
& \leq\left(\left\|x_{n}-x_{n+1}\right\|\right)\left(\left\|x_{n}-p\right\|+\left\|x_{n+1}-p\right\|\right)+2 \mu_{2}\left\|\left(y_{n}-\tilde{y}_{n}\right)-(p-\tilde{p})\right\|\left\|B_{2} y_{n}-B_{2} p\right\| \\
&+\alpha_{n}\left\|\gamma f\left(x_{n}\right)-\mu B_{3} W_{n} G y_{n}\right\|\left[2\left\|W_{n} G y_{n}-p\right\|+\alpha_{n}\left\|\gamma f\left(x_{n}\right)-\mu B_{3} W_{n} G y_{n}\right\|\right] .
\end{aligned}
$$

Since $\lim _{n \rightarrow \infty} \alpha_{n}=0, \lim _{n \rightarrow \infty}\left\|x_{n+1}-x_{n}\right\|=0$ and $\lim _{n \rightarrow \infty}\left\|B_{2} y_{n}-B_{2} p\right\|=0$, we deduce that

$$
\lim _{n \rightarrow \infty}\left\|\left(y_{n}-\tilde{y}_{n}\right)-(p-\tilde{p})\right\|=0
$$


Furthermore, it follows from (3.4), (3.18) and (3.21) that

$$
\begin{aligned}
\| x_{n+1}- & p \|^{2} \\
\leq & \left\|G y_{n}-p\right\|^{2}+\alpha_{n}\left\|\gamma f\left(x_{n}\right)-\mu B_{3} W_{n} G y_{n}\right\| \\
& \times\left[2\left\|W_{n} G y_{n}-p\right\|+\alpha_{n}\left\|\gamma f\left(x_{n}\right)-\mu B_{3} W_{n} G y_{n}\right\|\right] \\
\leq & \left\|w_{n}-p\right\|^{2}+\alpha_{n}\left\|\gamma f\left(x_{n}\right)-\mu B_{3} W_{n} G y_{n}\right\| \\
& \times\left[2\left\|W_{n} G y_{n}-p\right\|+\alpha_{n}\left\|\gamma f\left(x_{n}\right)-\mu B_{3} W_{n} G y_{n}\right\|\right] \\
\leq & \left\|x_{n}-p\right\|^{2}-\left\|\left(\tilde{y}_{n}-w_{n}\right)+(p-\tilde{p})\right\|^{2}+2 \mu_{1}\left\langle B_{1} \tilde{y}_{n}-B_{1} \tilde{p},\left(\tilde{y}_{n}-w_{n}\right)+(p-\tilde{p})\right\rangle \\
& +\alpha_{n}\left\|\gamma f\left(x_{n}\right)-\mu B_{3} W_{n} G y_{n}\right\|\left[2\left\|W_{n} G y_{n}-p\right\|+\alpha_{n}\left\|\gamma f\left(x_{n}\right)-\mu B_{3} W_{n} G y_{n}\right\|\right],
\end{aligned}
$$

which leads to

$$
\begin{aligned}
&\left\|\left(\tilde{y}_{n}-w_{n}\right)+(p-\tilde{p})\right\|^{2} \\
& \leq\left\|x_{n}-p\right\|^{2}-\left\|x_{n+1}-p\right\|^{2}+2 \mu_{1}\left\|B_{1} \tilde{y}_{n}-B_{1} \tilde{p}\right\|\left\|\left(\tilde{y}_{n}-w_{n}\right)+(p-\tilde{p})\right\| \\
&+\alpha_{n}\left\|\gamma f\left(x_{n}\right)-\mu B_{3} W_{n} G y_{n}\right\|\left[2\left\|W_{n} G y_{n}-p\right\|+\alpha_{n}\left\|\gamma f\left(x_{n}\right)-\mu B_{3} W_{n} G y_{n}\right\|\right] \\
& \leq\left(\left\|x_{n}-x_{n+1}\right\|\right)\left(\left\|x_{n}-p\right\|+\left\|x_{n+1}-p\right\|\right)+2 \mu_{1}\left\|B_{1} \tilde{y}_{n}-B_{1} \tilde{p}\right\|\left\|\left(\tilde{y}_{n}-w_{n}\right)+(p-\tilde{p})\right\| \\
&+\alpha_{n}\left\|\gamma f\left(x_{n}\right)-\mu B_{3} W_{n} G y_{n}\right\|\left[2\left\|W_{n} G y_{n}-p\right\|+\alpha_{n}\left\|\gamma f\left(x_{n}\right)-\mu B_{3} W_{n} G y_{n}\right\|\right] .
\end{aligned}
$$

Since $\lim _{n \rightarrow \infty} \alpha_{n}=0, \lim _{n \rightarrow \infty}\left\|x_{n+1}-x_{n}\right\|=0$ and $\lim _{n \rightarrow \infty}\left\|B_{1} \tilde{y}_{n}-B_{1} \tilde{p}\right\|=0$, we deduce that

$$
\lim _{n \rightarrow \infty}\left\|\left(\tilde{y}_{n}-w_{n}\right)+(p-\tilde{p})\right\|=0 .
$$

Note that

$$
\left\|y_{n}-w_{n}\right\| \leq\left\|\left(y_{n}-\tilde{y}_{n}\right)-(p-\tilde{p})\right\|+\left\|\left(\tilde{y}_{n}-w_{n}\right)+(p-\tilde{p})\right\| .
$$

Hence from (3.20) and (3.21), we get

$$
\lim _{n \rightarrow \infty}\left\|y_{n}-w_{n}\right\|=\lim _{n \rightarrow \infty}\left\|y_{n}-G y_{n}\right\|=0 .
$$

Next, we show that $\lim _{n \rightarrow \infty}\left\|x_{n}-u_{n, m}\right\|=0$ for every $1 \leq m \leq N$ and $\lim _{n \rightarrow \infty} \| x_{n}-$ $W G x_{n} \|=0$. Indeed, by Proposition 1.2(c), we obtain that for any $p \in \Omega$ and for each $1 \leq m \leq N$,

$$
\begin{aligned}
\left\|u_{n, m}-p\right\|^{2} & =\left\|T_{r_{n}, m}^{\left(F_{m}, \varphi\right)} x_{n}-T_{r_{n}, m}^{\left(F_{m}, \varphi\right)} p\right\|^{2} \\
& \leq\left\langle u_{n, m}-p, x_{n}-p\right\rangle \\
& =\frac{1}{2}\left[\left\|u_{n, m}-p\right\|^{2}+\left\|x_{n}-p\right\|^{2}-\left\|u_{n, m}-x_{n}\right\|^{2}\right] .
\end{aligned}
$$

That is,

$$
\left\|u_{n, m}-p\right\|^{2} \leq\left\|x_{n}-p\right\|^{2}-\left\|u_{n, m}-x_{n}\right\|^{2} .
$$


Then we have

$$
\begin{aligned}
\left\|z_{n}-p\right\|^{2} & =\left\|\sum_{m=1}^{N} \beta_{n, m} u_{n, m}-p\right\|^{2} \leq \sum_{m=1}^{N} \beta_{n, m}\left\|u_{n, m}-p\right\|^{2} \\
& \leq \sum_{m=1}^{N}\left(\left\|x_{n}-p\right\|^{2}-\left\|u_{n, m}-x_{n}\right\|^{2}\right) \\
& =\left\|x_{n}-p\right\|^{2}-\sum_{m=1}^{N}\left\|u_{n, m}-x_{n}\right\|^{2} .
\end{aligned}
$$

It follows that

$$
\left\|y_{n}-p\right\|^{2} \leq\left\|z_{n}-p\right\|^{2} \leq\left\|x_{n}-p\right\|^{2}-\sum_{m=1}^{N}\left\|u_{n, m}-x_{n}\right\|^{2} .
$$

It follows from (3.18) and (3.24) that

$$
\begin{aligned}
& \left\|x_{n+1}-p\right\|^{2} \\
& \leq\left\|y_{n}-p\right\|^{2}+\alpha_{n}\left\|\gamma f\left(x_{n}\right)-\mu B_{3} W_{n} G y_{n}\right\| \\
& \quad \times\left[2\left\|W_{n} G y_{n}-p\right\|+\alpha_{n}\left\|\gamma f\left(x_{n}\right)-\mu B_{3} W_{n} G y_{n}\right\|\right] \\
& \leq\left\|x_{n}-p\right\|^{2}-\sum_{m=1}^{N}\left\|u_{n, m}-x_{n}\right\|^{2}+\alpha_{n}\left\|\gamma f\left(x_{n}\right)-\mu B_{3} W_{n} G y_{n}\right\| \\
& \quad \times\left[2\left\|W_{n} G y_{n}-p\right\|+\alpha_{n}\left\|\gamma f\left(x_{n}\right)-\mu B_{3} W_{n} G y_{n}\right\|\right],
\end{aligned}
$$

which immediately implies that

$$
\begin{aligned}
\sum_{m=1}^{N} & \left\|u_{n, m}-x_{n}\right\|^{2} \\
\leq & \left\|x_{n}-p\right\|^{2}-\left\|x_{n+1}-p\right\|^{2} \\
& \quad+\alpha_{n}\left\|\gamma f\left(x_{n}\right)-\mu B_{3} W_{n} G y_{n}\right\|\left[2\left\|W_{n} G y_{n}-p\right\|+\alpha_{n}\left\|\gamma f\left(x_{n}\right)-\mu B_{3} W_{n} G y_{n}\right\|\right] \\
\leq & \left(\left\|x_{n}-x_{n+1}\right\|\right)\left(\left\|x_{n}-p\right\|+\left\|x_{n+1}-p\right\|\right) \\
\quad & +\alpha_{n}\left\|\gamma f\left(x_{n}\right)-\mu B_{3} W_{n} G y_{n}\right\|\left[2\left\|W_{n} G y_{n}-p\right\|+\alpha_{n}\left\|\gamma f\left(x_{n}\right)-\mu B_{3} W_{n} G y_{n}\right\|\right] .
\end{aligned}
$$

Since $\lim _{n \rightarrow \infty} \alpha_{n}=0$ and $\lim _{n \rightarrow \infty}\left\|x_{n}-x_{n+1}\right\|=0$, we deduce that

$$
\lim _{n \rightarrow \infty}\left\|u_{n, m}-x_{n}\right\|=0, \quad \forall 1 \leq m \leq N
$$

Since

$$
\left\|z_{n}-x_{n}\right\|=\left\|\sum_{m=1}^{N} \beta_{n, m} u_{n, m}-x_{n}\right\| \leq \sum_{m=1}^{N} \beta_{n, m}\left\|u_{n, m}-x_{n}\right\|,
$$


from $\lim _{n \rightarrow \infty}\left\|u_{n, m}-x_{n}\right\|=0$, we get

$$
\lim _{n \rightarrow \infty}\left\|z_{n}-x_{n}\right\|=0
$$

Notice that

$$
\begin{aligned}
\left\|y_{n}-x_{n}\right\| & \leq\left\|y_{n}-z_{n}\right\|+\left\|z_{n}-x_{n}\right\| \\
& \leq\left\|\delta_{n} W_{n} G z_{n}+\left(1-\delta_{n}\right) z_{n}-z_{n}\right\|+\left\|z_{n}-x_{n}\right\| \\
& =\delta_{n}\left\|W_{n} G z_{n}-z_{n}\right\|+\left\|z_{n}-x_{n}\right\| .
\end{aligned}
$$

Since $\delta_{n} \rightarrow 0$ and $\left\|z_{n}-x_{n}\right\| \rightarrow 0$, we get

$$
\lim _{n \rightarrow \infty}\left\|y_{n}-x_{n}\right\|=0
$$

Note that

$$
\begin{aligned}
\left\|x_{n}-W_{n} G x_{n}\right\| & \leq\left\|x_{n}-W_{n} G y_{n}\right\|+\left\|W_{n} G y_{n}-W_{n} G x_{n}\right\| \\
& \leq\left\|x_{n}-W_{n} G y_{n}\right\|+\left\|y_{n}-x_{n}\right\| .
\end{aligned}
$$

On the other hand,

$$
\begin{aligned}
\left\|x_{n}-W_{n} G y_{n}\right\| & \leq\left\|x_{n}-x_{n+1}\right\|+\left\|x_{n+1}-W_{n} G y_{n}\right\| \\
& =\left\|x_{n}-x_{n+1}\right\|+\left\|P_{C}\left[\alpha_{n} \gamma f\left(x_{n}\right)+\left(1-\alpha_{n} \mu B_{3}\right) W_{n} G y_{n}\right]-P_{C} W_{n} G y_{n}\right\| \\
& \leq\left\|x_{n}-x_{n+1}\right\|+\left\|\alpha_{n} \gamma f\left(x_{n}\right)+\left(1-\alpha_{n} \mu B_{3}\right) W_{n} G y_{n}-W_{n} G y_{n}\right\| \\
& =\left\|x_{n}-x_{n+1}\right\|+\alpha_{n}\left\|\gamma f\left(x_{n}\right)-\mu B_{3} W_{n} G y_{n}\right\| \rightarrow 0 .
\end{aligned}
$$

From $\lim _{n \rightarrow \infty}\left\|x_{n}-x_{n+1}\right\|=0$ and $\lim _{n \rightarrow \infty} \alpha_{n}=0$, we get

$$
\lim _{n \rightarrow \infty}\left\|x_{n}-W_{n} G x_{n}\right\|=0
$$

Note that

$$
\left\|x_{n}-W G x_{n}\right\| \leq\left\|x_{n}-W_{n} G x_{n}\right\|+\left\|W_{n} G x_{n}-W G x_{n}\right\| .
$$

From (3.30) and Remark 2.2, we see

$$
\lim _{n \rightarrow \infty}\left\|x_{n}-W G x_{n}\right\|=0
$$

Step 4. Now we shall prove

$$
\limsup _{n \rightarrow \infty}\left\langle x_{n}-x^{*},\left(\gamma f-\mu B_{3}\right) x^{*}\right\rangle \leq 0
$$

where $x^{*}$ is the unique solution of variational inequality (3.2). To show this, we take a subsequence $\left\{x_{n_{i}}\right\}$ of $\left\{x_{n}\right\}$ such that

$$
\limsup _{n \rightarrow \infty}\left\langle x_{n}-x^{*},\left(\gamma f-\mu B_{3}\right) x^{*}\right\rangle=\lim _{i \rightarrow \infty}\left\langle x_{n_{i}}-x^{*},\left(\gamma f-\mu B_{3}\right) x^{*}\right\rangle .
$$


Since $\left\{x_{n_{i}}\right\}$ is bounded, there exists a subsequence of $\left\{x_{n_{i}}\right\}$. Without loss of generality, we can still denote it by $\left\{x_{n_{i}}\right\}$ such that $x_{n_{i}} \rightarrow \omega$. Let us show $\omega \in \Omega:=\left(\bigcap_{n=1}^{\infty} F\left(T_{n}\right)\right) \cap$ $\left(\bigcap_{m=1}^{N} \operatorname{MEP}\left(F_{m}, \varphi\right)\right) \cap \Gamma$.

We first show $\omega \in \Gamma$. From $\left\|y_{n}-G y_{n}\right\| \rightarrow 0$ and $\left\|x_{n}-y_{n}\right\| \rightarrow 0$ and Lemma 2.5 (demiclosedness principle), we have $\omega \in F(G)=\Gamma$.

Next we show $\omega \in \bigcap_{m=1}^{N} \operatorname{MEP}\left(F_{m}, \varphi\right)$. Since $u_{n, m}=T_{r_{n, m}}^{\left(F_{m}, \varphi\right)} x_{n}$, we have

$$
F_{m}\left(u_{n, m}, y\right)+\varphi(y)-\varphi\left(u_{n, m}\right)+\frac{1}{r_{n, m}}\left\langle y-u_{n, m}, u_{n, m}-x_{n}\right\rangle \geq 0, \quad \forall y \in C .
$$

It follows from (A2) that

$$
\varphi(y)-\varphi\left(u_{n, m}\right)+\frac{1}{r_{n, m}}\left\langle y-u_{n, m}, u_{n, m}-x_{n}\right\rangle \geq F_{m}\left(y, u_{n, m}\right), \quad \forall y \in C .
$$

Replacing $n$ by $n_{i}$, we arrive at

$$
\varphi(y)-\varphi\left(u_{n_{i}, m}\right)+\left\langle\frac{u_{n_{i}, m}-x_{n_{i}}}{r_{n_{i}, m}}, y-u_{n_{i}, m}\right\rangle \geq F_{m}\left(y, u_{n_{i}, m}\right), \quad \forall y \in C .
$$

Put $y_{t_{m}}=t_{m} y+\left(1-t_{m}\right) \omega$ for all $t_{m} \in(0,1]$ and $y \in C$. Then from (3.33) we have

$$
0 \geq-\varphi\left(y_{t_{m}}\right)+\varphi\left(u_{n_{i}, m}\right)-\left\langle\frac{u_{n_{i}, m}-x_{n_{i}}}{r_{n_{i}, m}}, y_{t_{m}}-u_{n_{i}, m}\right\rangle+F_{m}\left(y_{t_{m}}, u_{n_{i}, m}\right) .
$$

So, from (A4), the weak lower semicontinuity of $\varphi, \frac{u_{n_{i}, m^{-}-x_{n_{i}}}}{r_{n_{i}, m}} \rightarrow 0$ and $u_{n_{i}} \rightarrow \omega$, we have

$$
0 \geq-\varphi\left(y_{t_{m}}\right)+\varphi(\omega)+F_{m}\left(y_{t_{m}}, \omega\right) \quad \text { as } i \rightarrow \infty
$$

From (A1), (A4) and (3.34), we also have

$$
\begin{aligned}
0 & =F_{m}\left(y_{t_{m}}, y_{t_{m}}\right)+\varphi\left(y_{t_{m}}\right)-\varphi\left(y_{t_{m}}\right) \\
& \leq t_{m} F_{m}\left(y_{t_{m}}, y\right)+\left(1-t_{m}\right) F_{m}\left(y_{t_{m}}, \omega\right)+t_{m} \varphi(y)-\left(1-t_{m}\right) \varphi(\omega)-\varphi\left(y_{t_{m}}\right) \\
& =t_{m}\left[F_{m}\left(y_{t_{m}}, y\right)+\varphi(y)-\varphi\left(y_{t_{m}}\right)\right]+\left(1-t_{m}\right)\left[F_{m}\left(y_{t_{m}}, \omega\right)+\varphi(\omega)-\varphi\left(y_{t_{m}}\right)\right] \\
& \leq t_{m}\left[F_{m}\left(y_{t_{m}}, y\right)+\varphi(y)-\varphi\left(y_{t_{m}}\right)\right]
\end{aligned}
$$

and hence

$$
0 \leq F_{m}\left(y_{t_{m}}, y\right)+\varphi(y)-\varphi\left(y_{t_{m}}\right) .
$$

Letting $t_{m} \rightarrow 0$, we have, for each $y \in C$,

$$
0 \leq F_{m}(\omega, y)+\varphi(y)-\varphi(\omega)
$$

This implies $\omega \in \operatorname{MEP}\left(F_{m}, \varphi\right)$ for each $1 \leq m \leq N$. Therefore $\omega \in \bigcap_{m=1}^{N} \operatorname{MEP}\left(F_{m}, \varphi\right)$. 
Last we show $\omega \in F(W)=\bigcap_{n=1}^{\infty} F\left(T_{n}\right)$. If $\omega \notin F(W)$. From Opial's lemma (Lemma 2.8), we have

$$
\begin{aligned}
\liminf _{i \rightarrow \infty}\left\|x_{n_{i}}-\omega\right\| & <\liminf _{i \rightarrow \infty}\left\|x_{n_{i}}-W G \omega\right\| \\
& \leq \liminf _{i \rightarrow \infty}\left(\left\|x_{n_{i}}-W G x_{n_{i}}\right\|+\left\|W G x_{n_{i}}-W G \omega\right\|\right) \\
& \leq \liminf _{i \rightarrow \infty}\left(\left\|x_{n_{i}}-W G x_{n_{i}}\right\|+\left\|x_{n_{i}}-\omega\right\|\right) .
\end{aligned}
$$

Since $\lim _{n \rightarrow \infty}\left\|x_{n}-W G x_{n}\right\|=0$, we have

$$
\liminf _{i \rightarrow \infty}\left\|x_{n_{i}}-\omega\right\|<\liminf _{i \rightarrow \infty}\left\|x_{n_{i}}-\omega\right\|
$$

This is a contradiction. Therefore, we have $\omega \in F(W)=\bigcap_{n=1}^{\infty} F\left(T_{n}\right)$, that is,

$$
\omega \in F(W) \cap\left(\bigcap_{m=1}^{N} \operatorname{MEP}\left(F_{m}, \varphi\right)\right) \cap \Gamma=\left(\bigcap_{n=1}^{\infty} F\left(T_{n}\right)\right) \cap\left(\bigcap_{m=1}^{N} \operatorname{MEP}\left(F_{m}, \varphi\right)\right) \cap \Gamma=\Omega
$$

Since $\omega \in \Omega$, due to (3.32) and the property of metric projection, we have

$$
\begin{aligned}
\limsup _{n \rightarrow \infty}\left\langle x_{n}-x^{*},\left(\gamma f-\mu B_{3}\right) x^{*}\right\rangle & =\lim _{i \rightarrow \infty}\left\langle x_{n_{i}}-x^{*},\left(\gamma f-\mu B_{3}\right) x^{*}\right\rangle \\
& =\left\langle\omega-x^{*},\left(\gamma f-\mu B_{3}\right) x^{*}\right\rangle \leq 0 .
\end{aligned}
$$

Step 5. Finally, we prove that $x_{n} \rightarrow x^{*}$ as $n \rightarrow \infty$. Setting $v_{n}=\alpha_{n} \gamma f\left(x_{n}\right)+(1-$ $\left.\alpha_{n} \mu B_{3}\right) W_{n} G y_{n}, \forall n \geq 1$. Then we can rewrite (3.1) as

$$
\left\{\begin{array}{l}
z_{n}=\sum_{m=1}^{N} \beta_{n, m} u_{n, m}, \\
y_{n}=\delta_{n} W_{n} G z_{n}+\left(1-\delta_{n}\right) z_{n} \\
x_{n+1}=P_{C} v_{n}
\end{array}\right.
$$

It follows from (3.3) and Proposition 1.1(i) that

$$
\begin{aligned}
&\left\|x_{n+1}-x^{*}\right\|^{2} \\
&=\left\langle P_{C} v_{n}-v_{n}, P_{C} v_{n}-x^{*}\right\rangle+\left\langle v_{n}-x^{*}, x_{n+1}-x^{*}\right\rangle \\
& \leq\left\langle v_{n}-x^{*}, x_{n+1}-x^{*}\right\rangle \\
&=\left\langle\alpha_{n} \gamma f\left(x_{n}\right)+\left(1-\alpha_{n} \mu B_{3}\right) W_{n} G y_{n}-x^{*}, x_{n+1}-x^{*}\right\rangle \\
&=\left\langle\alpha_{n}\left(\gamma f\left(x_{n}\right)-\mu B_{3} x^{*}\right)+\left(1-\alpha_{n} \mu B_{3}\right)\left(W_{n} G y_{n}-x^{*}\right), x_{n+1}-x^{*}\right\rangle \\
& \leq\left\langle\alpha_{n} \gamma\left(f\left(x_{n}\right)-f\left(x^{*}\right)\right)+\left(1-\alpha_{n} \mu B_{3}\right)\left(W_{n} G y_{n}-x^{*}\right), x_{n+1}-x^{*}\right\rangle \\
&+\alpha_{n}\left\langle\left(\gamma f-\mu B_{3}\right) x^{*}, x_{n+1}-x^{*}\right\rangle \\
& \leq\left\|\alpha_{n} \gamma\left(f\left(x_{n}\right)-f\left(x^{*}\right)\right)+\left(1-\alpha_{n} \mu B_{3}\right)\left(W_{n} G y_{n}-x^{*}\right)\right\|\left\|x_{n+1}-x^{*}\right\| \\
&+\alpha_{n}\left\langle\left(\gamma f-\mu B_{3}\right) x^{*}, x_{n+1}-x^{*}\right\rangle \\
& \leq {\left[\alpha_{n} \gamma l\left\|x_{n}-x^{*}\right\|+\left(1-\alpha_{n} \tau\right)\left\|W_{n} G y_{n}-x^{*}\right\|\right]\left\|x_{n+1}-x^{*}\right\| } \\
&+\alpha_{n}\left\langle\left(\gamma f-\mu B_{3}\right) x^{*}, x_{n+1}-x^{*}\right\rangle
\end{aligned}
$$




$$
\begin{aligned}
& \leq\left[\alpha_{n} \gamma l\left\|x_{n}-x^{*}\right\|+\left(1-\alpha_{n} \tau\right)\left\|x_{n}-x^{*}\right\|\right]\left\|x_{n+1}-x^{*}\right\|+\alpha_{n}\left\langle\left(\gamma f-\mu B_{3}\right) x^{*}, x_{n+1}-x^{*}\right\rangle \\
& \leq\left(1-\alpha_{n}(\tau-\gamma l)\right)\left\|x_{n}-x^{*}\right\|\left\|x_{n+1}-x^{*}\right\|+\alpha_{n}\left\langle\left(\gamma f-\mu B_{3}\right) x^{*}, x_{n+1}-x^{*}\right\rangle \\
& \leq \frac{1}{2}\left(1-\alpha_{n}(\tau-\gamma l)\right)\left(\left\|x_{n}-x^{*}\right\|^{2}+\left\|x_{n+1}-x^{*}\right\|^{2}\right)+\alpha_{n}\left\langle\left(\gamma f-\mu B_{3}\right) x^{*}, x_{n+1}-x^{*}\right\rangle,
\end{aligned}
$$

which implies that

$$
\begin{aligned}
&\left\|x_{n+1}-x^{*}\right\|^{2} \\
& \leq \frac{1-\alpha_{n}(\tau-\gamma l)}{1+\alpha_{n}(\tau-\gamma l)}\left\|x_{n}-x^{*}\right\|^{2}+\frac{\alpha_{n}}{1+\alpha_{n}(\tau-\gamma l)}\left\langle\left(\gamma f-\mu B_{3}\right) x^{*}, x_{n+1}-x^{*}\right\rangle \\
&=\left(1-\frac{2 \alpha_{n}(\tau-\gamma l)}{1+\alpha_{n}(\tau-\gamma l)}\right)\left\|x_{n}-x^{*}\right\|^{2} \\
& \quad+\frac{2 \alpha_{n}(\tau-\gamma l)}{1+\alpha_{n}(\tau-\gamma l)} \cdot \frac{1}{2(\tau-\gamma l)}\left\langle\left(\gamma f-\mu B_{3}\right) x^{*}, x_{n+1}-x^{*}\right\rangle \\
&=\left(1-\gamma_{n}\right)\left\|x_{n}-x^{*}\right\|^{2}+\sigma_{n} \gamma_{n},
\end{aligned}
$$

where $\gamma_{n}=\frac{2 \alpha_{n}(\tau-\gamma l)}{1+\alpha_{n}(\tau-\gamma l)}$ and

$$
\sigma_{n}=\frac{1}{2(\tau-\gamma l)}\left\langle\left(\gamma f-\mu B_{3}\right) x^{*}, x_{n+1}-x^{*}\right\rangle .
$$

It is easily seen that $\sum_{n=1}^{\infty} \gamma_{n}=\infty$ and $\lim \sup _{n \rightarrow \infty} \sigma_{n} \leq 0$ (due to condition (a) and (3.35)). According to Lemma 2.7 we conclude that $\left\{x_{n}\right\}$ converges strongly to $x^{*}$. This completes the proof.

Putting $T_{n} \equiv I$ the identity mapping, we obtain from Theorem 3.1 the following.

Corollary 3.1 Let $C$ be a nonempty closed convex subset of a Hilbert space $H$. Let $F_{m}$ be a sequence of bifunctions from $C \times C$ to $R$ satisfying (A1)-(A4), and let $\varphi: C \rightarrow R$ be a lower semicontinuous and convex function with restriction (B1) or (B2) for every $1 \leq m \leq N$, where $N$ denotes some positive integer. Let $\Theta_{1}, \Theta_{2}: C \times C \rightarrow R$ be two bifunctions satisfying (A1)-(A4), the mapping $B_{i}: C \rightarrow H$ be $\zeta_{i}$-inverse strongly monotone for $i=1,2, B_{3}$ be a $\kappa$-Lipschitz and $\eta$-strongly monotone operator with constants $\kappa, \eta>0$, and let $f: H \rightarrow H$ be an l-Lipschitz mapping with constant $l>0$. Suppose that $0<\mu<2 \eta / \kappa^{2}$ and $0<\gamma l<\tau$, where $\tau=1-\sqrt{1-\mu\left(2 \eta-\mu \kappa^{2}\right)}$. Assume that $\Omega:=\left(\bigcap_{m=1}^{N} \operatorname{MEP}\left(F_{m}, \varphi\right)\right) \cap \Gamma \neq \emptyset$, where $\Gamma$ is a fixed point set of the mapping $G=T_{\mu_{1}}^{\Theta_{1}}\left(I-\mu_{1} B_{1}\right) T_{\mu_{2}}^{\Theta_{2}}\left(I-\mu_{2} B_{2}\right)$ with $\mu_{i} \in\left(0,2 \zeta_{i}\right)$ for $i=1,2$. Let $\left\{\alpha_{n}\right\},\left\{\delta_{n}\right\},\left\{\beta_{n, 1}\right\}, \ldots$ and $\left\{\beta_{n, N}\right\}$ be sequences in $[0,1]$ and $\left\{r_{n, m}\right\}$ be a sequence in $(0, \infty)$ for every $1 \leq m \leq N$ such that:

(a) $\lim _{n \rightarrow \infty} \alpha_{n}=0, \sum_{n=1}^{\infty} \alpha_{n}=\infty$ and $\sum_{n=1}^{\infty}\left|\alpha_{n+1}-\alpha_{n}\right|<\infty$;

(b) $\sum_{m=1}^{N} \beta_{n, m}=1$ and $\sum_{n=1}^{\infty}\left|\beta_{n+1, m}-\beta_{n, m}\right|<\infty$ for each $1 \leq m \leq N$;

(c) $\lim _{n \rightarrow \infty} \delta_{n}=0$ and $\sum_{n=1}^{\infty}\left|\delta_{n+1}-\delta_{n}\right|<\infty$;

(d) $\liminf _{n \rightarrow \infty} r_{n, m}>0$ and $\sum_{n=1}^{\infty}\left|r_{n+1, m}-r_{n, m}\right|<\infty$ for each $1 \leq m \leq N$.

Given $x_{1} \in H$ arbitrarily, the sequence $\left\{x_{n}\right\}$ is generated iteratively by

$$
\left\{\begin{array}{l}
y_{n}=\delta_{n} G\left(\sum_{m=1}^{N} \beta_{n, m} u_{n, m}\right)+\left(1-\delta_{n}\right)\left(\sum_{m=1}^{N} \beta_{n, m} u_{n, m}\right) \\
x_{n+1}=P_{C}\left[\alpha_{n} \gamma f\left(x_{n}\right)+\left(1-\alpha_{n} \mu B_{3}\right) G y_{n}\right], \quad \forall n \geq 1
\end{array}\right.
$$


where $u_{n, m}$ is such that

$$
F_{m}\left(u_{n, m}, y\right)+\varphi(y)-\varphi\left(u_{n, m}\right)+\frac{1}{r_{n, m}}\left\langle y-u_{n, m}, u_{n, m}-x_{n}\right\rangle \geq 0, \quad \forall y \in C,
$$

for each $1 \leq m \leq N$. Then the sequence $\left\{x_{n}\right\}$ defined by (3.37) converges strongly to $x^{*} \in \Omega$, as $n \rightarrow \infty$, where $x^{*}$ is the unique solution of the variational inequality

$$
\left\langle\left(\gamma f-\mu B_{3}\right) x^{*}, z-x^{*}\right\rangle \leq 0, \quad \forall z \in \Omega
$$

If $N=1$, we obtain from Theorem 3.1 the following.

Corollary 3.2 Let $C$ be a nonempty closed convex subset of a Hilbert space $H$. Let $F$ be a sequence of bifunctions from $C \times C$ to $R$ satisfying (A1)-(A4), and let $\varphi: C \rightarrow R$ be a lower semicontinuous and convex function with restriction (B1) or (B2). Let $\Theta_{1}, \Theta_{2}: C \times C \rightarrow$ $R$ be two bifunctions satisfying (A1)-(A4), the mapping $B_{i}: C \rightarrow H$ be $\zeta_{i}$-inverse strongly monotone for $i=1,2, B_{3}$ be a $\kappa$-Lipschitz and $\eta$-strongly monotone operator with constants $\kappa, \eta>0$, and let $f: H \rightarrow H$ be an l-Lipschitz mapping with constant $l \geq 0$. Let $\left\{T_{n}\right\}_{n=1}^{\infty}$ be a sequence of nonexpansive mappings on $C$ and $\left\{\lambda_{n}\right\}$ be a sequence in $(0, b]$ for some $b \in(0,1)$. Suppose that $0<\mu<2 \eta / \kappa^{2}$ and $0<\gamma l<\tau$, where $\tau=1-\sqrt{1-\mu\left(2 \eta-\mu \kappa^{2}\right)}$. Assume that $\Omega:=\left(\bigcap_{n=1}^{\infty} F\left(T_{n}\right)\right) \cap(\operatorname{MEP}(F, \varphi)) \cap \Gamma \neq \emptyset$, where $\Gamma$ is a fixed point set of the mapping $G=T_{\mu_{1}}^{\Theta_{1}}\left(I-\mu_{1} B_{1}\right) T_{\mu_{2}}^{\Theta_{2}}\left(I-\mu_{2} B_{2}\right)$ with $\mu_{i} \in\left(0,2 \zeta_{i}\right)$ for $i=1,2$. Let $\left\{\alpha_{n}\right\},\left\{\delta_{n}\right\}$ be sequences in $[0,1]$ and $\left\{r_{n}\right\}$ be a sequence in $(0, \infty)$ such that:

(a) $\lim _{n \rightarrow \infty} \alpha_{n}=0, \sum_{n=1}^{\infty} \alpha_{n}=\infty$ and $\sum_{n=1}^{\infty}\left|\alpha_{n+1}-\alpha_{n}\right|<\infty$;

(b) $\lim _{n \rightarrow \infty} \delta_{n}=0$ and $\sum_{n=1}^{\infty}\left|\delta_{n+1}-\delta_{n}\right|<\infty$;

(c) $\liminf _{n \rightarrow \infty} r_{n}>0$ and $\sum_{n=1}^{\infty}\left|r_{n+1}-r_{n}\right|<\infty$.

Given $x_{1} \in H$ arbitrarily, the sequence $\left\{x_{n}\right\}$ is generated iteratively by

$$
\left\{\begin{array}{l}
F\left(u_{n}, y\right)+\varphi(y)-\varphi\left(u_{n}\right)+\frac{1}{r_{n}}\left\langle y-u_{n}, u_{n}-x_{n}\right\rangle \geq 0, \quad \forall y \in C, \\
y_{n}=\delta_{n} W_{n} G u_{n}+\left(1-\delta_{n}\right) u_{n}, \\
x_{n+1}=P_{C}\left[\alpha_{n} \gamma f\left(x_{n}\right)+\left(1-\alpha_{n} \mu B_{3}\right) W_{n} G y_{n}\right], \quad \forall n \geq 1,
\end{array}\right.
$$

where $W_{n}$ is defined by (1.17). Then the sequence $\left\{x_{n}\right\}$ defined by (3.38) converges strongly to $x^{*} \in \Omega$, as $n \rightarrow \infty$, where $x^{*}$ is the unique solution of the variational inequality

$$
\left\langle\left(\gamma f-\mu B_{3}\right) x^{*}, z-x^{*}\right\rangle \leq 0, \quad \forall z \in \Omega
$$

If $\varphi \equiv 0$, we obtain from Theorem 3.1 the following.

Corollary 3.3 Let $C$ be a nonempty closed convex subset of a Hilbert space H. Let $F_{m}$ be a sequence of bifunctions from $C \times C$ to $R$ satisfying (A1)-(A4) for every $1 \leq m \leq N$, where $N$ denotes some positive integer. Let $\Theta_{1}, \Theta_{2}: C \times C \rightarrow R$ be two bifunctions satisfying (A1)-(A4), the mapping $B_{i}: C \rightarrow H$ be $\zeta_{i}$-inverse strongly monotone for $i=1,2$, $B_{3}$ be a $\kappa$-Lipschitz and $\eta$-strongly monotone operator with constants $\kappa, \eta>0$, and let $f: H \rightarrow H$ be an l-Lipschitz mapping with constant $l \geq 0$. Let $\left\{T_{n}\right\}_{n=1}^{\infty}$ be a sequence of nonexpansive mappings on $C$ and $\left\{\lambda_{n}\right\}$ be a sequence in $(0, b]$ for some $b \in(0,1)$. Suppose that $0<\mu<2 \eta / \kappa^{2}$ and $0<\gamma l<\tau$, where $\tau=1-\sqrt{1-\mu\left(2 \eta-\mu \kappa^{2}\right)}$. Assume that 
$\Omega:=\left(\bigcap_{n=1}^{\infty} F\left(T_{n}\right)\right) \cap\left(\bigcap_{m=1}^{N} \operatorname{EP}\left(F_{m}\right)\right) \cap \Gamma \neq \emptyset$, where $\Gamma$ is a fixed point set of the mapping $G=T_{\mu_{1}}^{\Theta_{1}}\left(I-\mu_{1} B_{1}\right) T_{\mu_{2}}^{\Theta_{2}}\left(I-\mu_{2} B_{2}\right)$ with $\mu_{i} \in\left(0,2 \zeta_{i}\right)$ for $i=1,2$. Let $\left\{\alpha_{n}\right\},\left\{\delta_{n}\right\},\left\{\beta_{n, 1}\right\}, \ldots$ and $\left\{\beta_{n, N}\right\}$ be sequences in $[0,1]$ and $\left\{r_{n, m}\right\}$ be a sequence in $(0, \infty)$ for every $1 \leq m \leq N$ such that:

(a) $\lim _{n \rightarrow \infty} \alpha_{n}=0, \sum_{n=1}^{\infty} \alpha_{n}=\infty$ and $\sum_{n=1}^{\infty}\left|\alpha_{n+1}-\alpha_{n}\right|<\infty$;

(b) $\sum_{m=1}^{N} \beta_{n, m}=1$ and $\sum_{n=1}^{\infty}\left|\beta_{n+1, m}-\beta_{n, m}\right|<\infty$ for each $1 \leq m \leq N$;

(c) $\lim _{n \rightarrow \infty} \delta_{n}=0$ and $\sum_{n=1}^{\infty}\left|\delta_{n+1}-\delta_{n}\right|<\infty$;

(d) $\liminf _{n \rightarrow \infty} r_{n, m}>0$ and $\sum_{n=1}^{\infty}\left|r_{n+1, m}-r_{n, m}\right|<\infty$ for each $1 \leq m \leq N$.

Given $x_{1} \in H$ arbitrarily, the sequence $\left\{x_{n}\right\}$ is generated iteratively by

$$
\left\{\begin{array}{l}
y_{n}=\delta_{n} W_{n} G\left(\sum_{m=1}^{N} \beta_{n, m} u_{n, m}\right)+\left(1-\delta_{n}\right)\left(\sum_{m=1}^{N} \beta_{n, m} u_{n, m}\right) \\
x_{n+1}=P_{C}\left[\alpha_{n} \gamma f\left(x_{n}\right)+\left(1-\alpha_{n} \mu B_{3}\right) W_{n} G y_{n}\right], \quad \forall n \geq 1
\end{array}\right.
$$

where $u_{n, m}$ is such that

$$
F_{m}\left(u_{n, m}, y\right)+\frac{1}{r_{n, m}}\left\langle y-u_{n, m}, u_{n, m}-x_{n}\right\rangle \geq 0, \quad \forall y \in C,
$$

for each $1 \leq m \leq N, W_{n}$ is defined by (1.17). Then the sequence $\left\{x_{n}\right\}$ defined by (3.39) converges strongly to $x^{*} \in \Omega$, as $n \rightarrow \infty$, where $x^{*}$ is the unique solution of the variational inequality

$$
\left\langle\left(\gamma f-\mu B_{3}\right) x^{*}, z-x^{*}\right\rangle \leq 0, \quad \forall z \in \Omega \text {. }
$$

If $\Theta_{1} \equiv \Theta_{2} \equiv 0$, we obtain from Theorem 3.1 the following.

Corollary 3.4 Let $C$ be a nonempty closed convex subset of a Hilbert space $H$. Let $F_{m}$ be a sequence of bifunctions from $C \times C$ to $R$ satisfying (A1)-(A4), and let $\varphi: C \rightarrow R$ be a lower semicontinuous and convex function with restriction (B1) or (B2) for every $1 \leq m \leq N$, where $N$ denotes some positive integer. Let the mapping $B_{i}: C \rightarrow H$ be $\zeta_{i}$-inverse strongly monotone for $i=1,2, B_{3}$ be a $\kappa$-Lipschitz and $\eta$-strongly monotone operator with constants $\kappa, \eta>0$, and let $f: H \rightarrow H$ be an l-Lipschitz mapping with constant $l \geq 0$. Let $\left\{T_{n}\right\}_{n=1}^{\infty}$ be a sequence of nonexpansive mappings on $C$ and $\left\{\lambda_{n}\right\}$ be a sequence in $(0, b]$ for some $b \in(0,1)$. Suppose that $0<\mu<2 \eta / \kappa^{2}$ and $0<\gamma l<\tau$, where $\tau=1-\sqrt{1-\mu\left(2 \eta-\mu \kappa^{2}\right)}$. Assume that $\Omega:=\left(\bigcap_{n=1}^{\infty} F\left(T_{n}\right)\right) \cap\left(\bigcap_{m=1}^{N} \operatorname{MEP}\left(F_{m}, \varphi\right)\right) \cap \Gamma \neq \emptyset$, where $\Gamma$ is a fixed point set of the mapping $G=P_{C}\left(I-\mu_{1} B_{1}\right) P_{C}\left(I-\mu_{2} B_{2}\right)$ with $\mu_{i} \in\left(0,2 \zeta_{i}\right)$ for $i=1,2$. Let $\left\{\alpha_{n}\right\},\left\{\delta_{n}\right\},\left\{\beta_{n, 1}\right\}, \ldots$ and $\left\{\beta_{n, N}\right\}$ be sequences in $[0,1]$ and $\left\{r_{n, m}\right\}$ be a sequence in $(0, \infty)$ for every $1 \leq m \leq N$ such that:

(a) $\lim _{n \rightarrow \infty} \alpha_{n}=0, \sum_{n=1}^{\infty} \alpha_{n}=\infty$ and $\sum_{n=1}^{\infty}\left|\alpha_{n+1}-\alpha_{n}\right|<\infty$;

(b) $\sum_{m=1}^{N} \beta_{n, m}=1$ and $\sum_{n=1}^{\infty}\left|\beta_{n+1, m}-\beta_{n, m}\right|<\infty$ for each $1 \leq m \leq N$;

(c) $\lim _{n \rightarrow \infty} \delta_{n}=0$ and $\sum_{n=1}^{\infty}\left|\delta_{n+1}-\delta_{n}\right|<\infty$;

(d) $\liminf _{n \rightarrow \infty} r_{n, m}>0$ and $\sum_{n=1}^{\infty}\left|r_{n+1, m}-r_{n, m}\right|<\infty$ for each $1 \leq m \leq N$.

Given $x_{1} \in H$ arbitrarily, the sequence $\left\{x_{n}\right\}$ is generated iteratively by

$$
\left\{\begin{array}{l}
y_{n}=\delta_{n} W_{n} G\left(\sum_{m=1}^{N} \beta_{n, m} u_{n, m}\right)+\left(1-\delta_{n}\right)\left(\sum_{m=1}^{N} \beta_{n, m} u_{n, m}\right) \\
x_{n+1}=P_{C}\left[\alpha_{n} \gamma f\left(x_{n}\right)+\left(1-\alpha_{n} \mu B_{3}\right) W_{n} G y_{n}\right], \quad \forall n \geq 1
\end{array}\right.
$$

where $u_{n, m}$ is such that

$$
F_{m}\left(u_{n, m}, y\right)+\varphi(y)-\varphi\left(u_{n, m}\right)+\frac{1}{r_{n, m}}\left\langle y-u_{n, m}, u_{n, m}-x_{n}\right\rangle \geq 0, \quad \forall y \in C,
$$


for each $1 \leq m \leq N, W_{n}$ is defined by (1.17). Then the sequence $\left\{x_{n}\right\}$ defined by (3.40) converges strongly to $x^{*} \in \Omega$, as $n \rightarrow \infty$, where $x^{*}$ is the unique solution of the variational inequality

$$
\left\langle\left(\gamma f-\mu B_{3}\right) x^{*}, z-x^{*}\right\rangle \leq 0, \quad \forall z \in \Omega
$$

\section{Competing interests}

The authors declare that they have no competing interest.

\section{Authors' contributions}

All authors contributed equally and significantly in writing this article. All authors read and approved the finial manuscript.

\section{Author details}

'Department of Mathematics, Shanghai Normal University, Shanghai, 200234, China. ${ }^{2}$ College of Science, Zhongyuan

University of Technology, Zhengzhou, 450007, China.

\section{Acknowledgements}

All the authors were partially supported by the National Science Foundation of China (11071169) and PhD Program Foundation of the Ministry of Education of China (20123127110002).

Received: 12 September 2014 Accepted: 12 November 2014 Published: 26 Nov 2014

\section{References}

1. Moudafi, A: Viscosity approximation methods for fixed-points problems. J. Math. Anal. Appl. 241, $46-55$ (2000)

2. Ceng, LC, Yao, JC: A hybrid iterative scheme for mixed equilibrium problems and fixed point problems. J. Comput. Appl. Math. 214, 186-201 (2008)

3. Chang, SS, Lee, HWJ, Chan, CK: A new method for solving equilibrium problem fixed point problem and variational inequality problem with application to optimization. Nonlinear Anal. 70, 3307-3319 (2009)

4. Zeng, LC, Yao, JC: Modified combined relaxation method for general monotone equilibrium problems in Hilbert spaces. J. Optim. Theory Appl. 131, 469-483 (2006)

5. Takahashi, S, Takahashi, W: Viscosity approximation methods for equilibrium problems and fixed point problems in Hilbert spaces. J. Math. Anal. Appl. 331, 506-515 (2007)

6. Yao, Y, Liou, YC, Yao, JC: Convergence theorem for equilibrium problems and fixed point problems of infinite family of nonexpansive mapping. Fixed Point Theory Appl. 2007, Article ID 064363 (2007)

7. Rattanaseeha, K: The general iterative methods for equilibrium problems and fixed point problems of countable family of nonexpansive mappings in Hilbert spaces. J. Inequal. Appl. 2013, 153 (2013)

8. Ceng, LC, Yao, JC: A relaxed extragradient-like method for a generalized mixed equilibrium problems, a general system of generalized equilibria and a fixed point problem. Nonlinear Anal. 72, 1922-1937 (2010)

9. Ceng, LC, Guu, SM, Yao, JC: Hybrid iterative method for finding common solutions of generalized mixed equilibrium and fixed point problem. Fixed Point Theory Appl. 2012, 92 (2012)

10. Lions, JL, Stampacchia, G: Variational inequalities. Commun. Pure Appl. Math. 20, 493-512 (1967)

11. Zeng, LC: Iterative algorithms for finding approximate solutions for general strongly nonlinear variational inequalities. J. Math. Anal. Appl. 187, 352-360 (1994)

12. Ceng, LC, Teboulle, M, Yao, JC: Weak convergence of an iterative method for pseudomonotone variational inequalities and fixed point problems. J. Optim. Theory Appl. 146, 19-31 (2010)

13. Zeng, LC: Iterative algorithm for finding approximate solutions to completely generalized strongly nonlinear quasivariational inequalities. J. Math. Anal. Appl. 201, 182-194 (1996)

14. Yao, Y, Yao, JC: On modified iterative method for nonexpansive mappings and monotone mappings. Appl. Math. Comput. 186, 1551-1558 (2007)

15. Zeng, LC, Yao, JC: Strong convergence theorem by an extragradient method for fixed point problems and variational inequality problems. Taiwan. J. Math. 10, 1293-1303 (2006)

16. Ceng, LC, Wang, CY, Yao, JC: Strong convergence theorems by a relaxed extragradient method for a general system of variational inequalities. Math. Methods Oper. Res. 67, 375-390 (2008)

17. Xu, HK: Viscosity approximation methods for nonexpansive mappings. J. Math. Anal. Appl. 298, $279-291$ (2004)

18. Marino, G, Xu, HK: A general iterative method for nonexpansive mapping in Hilbert space. J. Math. Anal. Appl. 318, 43-52 (2006)

19. Plubtieng, S, Punpaeng, R: A general iterative method for equilibrium problems and fixed point problems in Hilbert spaces. J. Math. Anal. Appl. 336, 455-469 (2007)

20. Yamada, I: The hybrid steepest descent for the variational inequality problems over the intersection of nonexpansive mapping. In: Butnariu, D, Censor, Y, Reich, S (eds.) Inherently Parallel Algorithms in Feasibility and Optimization and Their Applications, pp. 473-504. Elsevier, New York (2001)

21. Tian, M: A general iterative method based on the hybrid steepest descent scheme for nonexpansive mappings in Hilbert space. In: 2010 International Conference on Computational Intelligence and Software Engineering (CISE) (2010)

22. Ceng, LC, Ansari, QH, Yao, JC: Some iterative methods for finding fixed points and for solving constrained convex minimization problems. Nonlinear Anal. 74, 5286-5302 (2011) 
23. Chen, R: Iterative schemes for fixed point computation of nonexpansive mappings. Abstr. Appl. Anal. 2012, Article ID $469270(2012)$

24. Wang, XJ, Ceng, LC, Hu, HY, Li, SX: General iterative algorithms for mixed equilibrium problems, variational inequalities and fixed point problems. Fixed Point Theory Appl. 2014, 80 (2014)

25. Marino, G, Muglia, L, Yao, Y: Viscosity methods for common solutions for equilibrium and variational inequality problems via multi-steps iterative algorithms and common fixed points. Nonlinear Anal. 75, 1787-1798 (2012)

26. Sahu, DR, Colao, V, Marino, G: Strong convergence theorems for approximating common fixed points of families of nonexpansive mappings and applications. J. Glob. Optim. 56, 1631-1651 (2013). doi:10.1007/s10898-012-9929-9

27. O'Hara, JG, Pillay, P, Xu, HK: Iterative approaches to convex feasibility problems in Banach spaces. Nonlinear Anal. 64, 2002-2042 (2006)

28. Goebel, K, Kirk, WA: Topics on Metric Fixed Point Theory. Cambridge University Press, Cambridge (1990)

29. Xu, HK: Iterative algorithms for nonlinear operators. J. Lond. Math. Soc. 66, 240-256 (2002)

10.1186/1029-242X-2014-470

Cite this article as: Hu et al.: General iterative algorithms for mixed equilibrium problems, a general system of generalized equilibria and fixed point problems. Journal of Inequalities and Applications 2014, 2014:470

\section{Submit your manuscript to a SpringerOpen ${ }^{\ominus}$ journal and benefit from:}

- Convenient online submission

- Rigorous peer review

- Immediate publication on acceptance

- Open access: articles freely available online

- High visibility within the field

- Retaining the copyright to your article 